\title{
ESTIMATING REFRACTIVE INDEX SPECTRA IN REGIONS OF CLEAR AIR TURBULENCE
}

by

\author{
J. J. Stephens \\ E. R. Reiter
}

ANTENNAS AND PROPAGATION DIVISION

ELECTRICAL ENGINEERING RESEARCH LABORATORY

THE UNIVERSITY OF TEXAS

AUSTIN, TEXAS

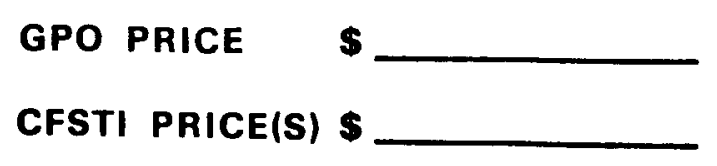

Report No. P-12

5 October 1966

Hard copy $(H C) \frac{3.00}{.50}$

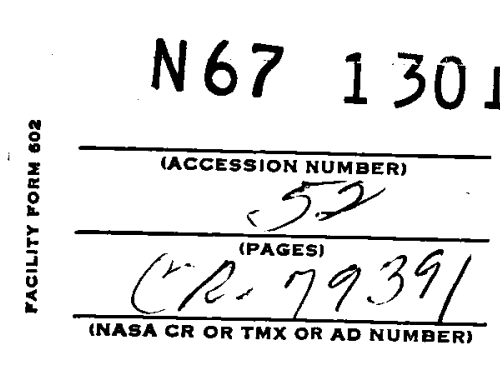

ff 653 Julv 65

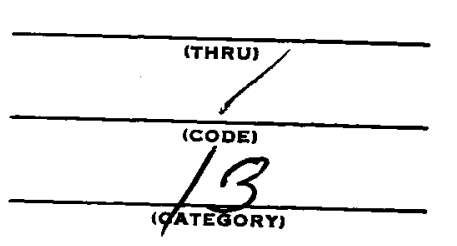

Prepared Under

NASA Grant NGR 44-012-048 


\title{
ESTIMATING REFRACTIVE INDEX SPECTRA IN REGIONS
} OF CLEAR-AIR TURBULENCE

by
J. J. Stephens
E. R. Reiter

ANT ENNAS AND PROPAGATION DIVISION ELECTRICAL ENGINEERING RESEARCH LABORATORY

THE UNIVERSIT Y OF TEXAS

Austin, Texas

\author{
Report No. P-12 \\ 5 Ootolber 1966
}

Prepared Under

NASA Grant NGR 44-012-048 


\section{PREFACE}

This is the first technical report prepared under NASA Grant NGR 44-012-048. It is intended to serve as a background in the meteorological aspects of the problem for further theoretical and experimental studies on the technique for detection of CAT.

The second report which will follow in a few weeks will be entitled "Remote Detection of CAT" by Dr. B. M. Fannin. This second report will examine the existing theories on radar return from disturbed refractive index regions.

A third report which is in the process of preparation will be concerned with equipment for direct measurement of refractive index differences and the examination of the initial data taken on a 270 foot tower. The results of these measurements should shed considerable light on the nature of refractive index anomalies associated with refractive index variation of the atmosphere.

A fourth aspect of the research is concerned with the use of radar for measuring the return from the refractive index variation in the atmosphere. Analysis of experimental programs is currently under way. Preliminary proposals have been made to the Electronics Research Center for unique tests which would measure scattering from radar beams and the associated refractive index anomalies. It is hoped that this program can be continued in an extension of the grant period. 


\title{
CONCLUSIONS
}

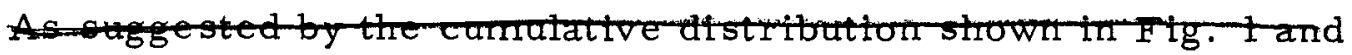

the summay shown in Table 2, clear-air turbulence patches average from 500 to 3000 feet in depth and one-half have horizontal dimensions less than 20 miles.

Clear-air turbulence occurs preferentially on the boundaries of shallow, thermally-stable baroclinic zones in the vicinity of the jet stream. The average percentage frequency in the jet stream vicinity is shown in Fig. 2. A schematic presentation of the variation with flow curvature is given in-Fig: -4 . These indicate a preference for occurrence on the cyclone side of the jet core and topographic effects may enhance these frequencies.
\end{abstract}

The refractive index spectrum for scales in the inertial subrange in the presence of clear-air turbulence can be expressed in terms of the mechanical energy. For stable stratification, the dependence suggested by Tatarski [61] may be used to provide consistent estimates.

The refractive index spectral estimates for dry air fluctuations made here are less than those found by other investigators for example, Tatarski[61], Atlas et al. [2]) by more than $10 \mathrm{db}$. Since the scattering at any angle is directly proportional to the spectral amplitude, the radar return will be correspondingly less than previous estimates. 
TABLE OF CONTENTS

$\begin{array}{lc} & \text { Page } \\ \text { PREFACE } & \text { ii } \\ \text { CONCLUSIONS } & \mathrm{iii} \\ \text { LIST OF FIGURES } & \mathrm{v} \\ \text { LIST OF TABLES } & \mathrm{vi} \\ \text { INTRODUCTION } & 1 \\ \text { LOCATIONS AND DIMENSIONS OF CAT } & 2 \\ \text { MECHANISM, SIGNATURE AND STRUCTURE OF CAT } & 16 \\ \text { REFRACTIVE INDEX SPECTRA } & 22 \\ \text { REFERENCES } & 40\end{array}$




\section{LIST OF FIGURES}

No.

1 Horizontal extent of clear-air turbulence encountered in project jet stream

2 Average distribution of per cent of time turbulence of light or greater intensity is encountered in the jet stream

3 Idealized jet stream model cross section

4 Idealized models of turbulent regions in the vicinity of the jet stream

5 Cross section of conditions associated with a typical mountain wave

7 Percentage of turbulence occurrences in the Patterson area with the $850 \mathrm{mb}$ central wind direction $\left(085-265^{\circ} \pm 30^{\circ}\right)$ normal to the central ridge

8 Percentage of turbulence occurrences in the Patterson area with the $850 \mathrm{mb}$ central wind direction $\left(175-355^{\circ} \pm 59^{\circ}\right)$ parallel to the central ridge

9 Schematic diagram of air flow in the vicinity of an idealized gravitational shearing wave

10 "Smoothed" spectra of $u-, v-$, and $w$-components of turbulence measured during flights $18 \mathrm{~B}$ and $18 \mathrm{D}$

11 Schematic refractive index spectrum as a function of wave number indicating typical ranges and the narrow band filter which determines scattering from turbulent fluctuations

$12 \quad$ Flight cross section analysis

$13 \quad$ Flight cross section analysis

14 Assumed $f\left(p_{1} T\right)$ relationship as a function of pressure 
15 Vertical cross section of temperature $\left({ }^{\circ} \mathrm{C}\right)$ from the low-pressure (left) to high pressure (right) side of the jet stream. Regions of moderate turbulence shaded. Soundings at $A$ and $B$ used for sample refractive index spectra computations

16 Smoothed profiles of potential temperature gradient Fluctuation amplitude coefficient $\mathrm{C}_{N}^{2}$ as a function of altitude for soundings $A$ and $B$

T ABLES

$1 \quad$ Turbulence criteria

2 Characteristics of various CAT observations

3 Vertical wind shear for different temperature discontinuities and critical wave lengths at an interface 


\title{
ESTIMATING REFRACTIVE INDEX SPECTRA IN REGIONS \\ OF CLEAR-AIR TURBULENCE
}

\author{
J. J. Stephens \\ E. R. Reiter 1
}

\section{INTRODUCTION}

Clear-air turbulence (CAT) may be defined as bumpiness in flight through clear air, i. e., away from clouds and at heights exceeding 15, 000 feet MSL. The turbulent mechanical energy associated with CAT must be of sufficient magnitude at the proper wavelengths to affect an aircraft flying in the region. Low-level turbulence induced mechanically by surface roughness is excluded from consideration, as is turbulence encountered in deep convective currents associated with cumulus clouds.

The problem understudy here is the assessment of the spectrum of refractive index fluctuations to be expected in regions of moderate to severe CAT. Scattering of electromagnetic waves by turbulent inhomogeneities in refractive index will betreated in a later report by B. M. Fannin. Taken together, these constitute an alternate solution to the approach by Atlas, Hardy and Naito [2].

1 Professor and Acting Chairman, Department of Atmospheric Science, Colorado State University, Fort Collins, Colorado. 


\section{LOCATIONS AND DIMENSIONS OF CAT}

Clear-air turbulence is found in the upper troposphere and stratosphere, principally in shallow layers in the jet stream vicinity, in waves leeward of mountain ranges, and to a lesser extent in association with upper troughs and lows. Although light turbulence may be expected in layers of nearly adiabalic stratification, moderate to severe CAT appears to occur preferentially on the boundaries of thermally stable, baroclinic zones.

Various descriptive terms have been used to characterize the intensity of CAT. Criteria developed by the NACA Subcommittee on Meteorological Problems are shown in Table 1 along with objective criteria for use with the VGH meter ${ }^{2}$ (Colson [15], Endlich [20]). The derived vertical, sharp-edge equivalent gust depends upon the aircraft response characteristics, as well as the atmospheric turbulent energy spectrum (see, for example, Reiter [46]). This led to a modified VGH instrument measuring horizontal gusts (Endlich [20]).

The horizontal extent of clear-air turbulence patches encountered in Project Jet Stream flights is shown in Fig. 1, after Cunningham [17]. More than $50 \%$ of the turbulent patches were less than 20 miles in extent. Nearly one-third were less than 10 miles. Cunningham considered that

This instrument records velocity (air speed), gusts (acceleration), and height. 


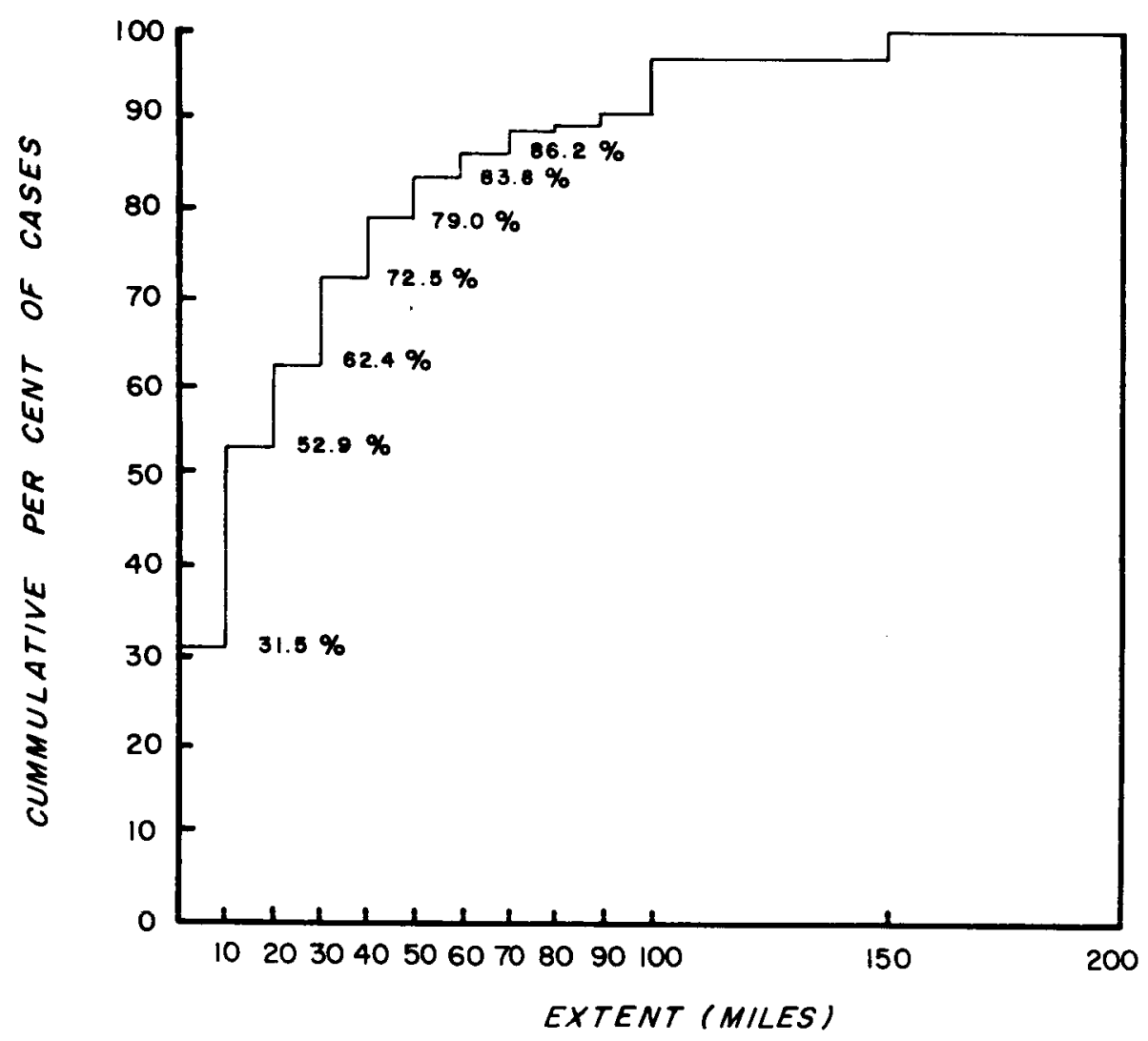

FIG. I. HORIZONTAL EXTENT OF CLEAR-AIR TURBULENCE ENCOUNTERED IN PROJECT JET STREAM (Cunningham [17]) 


\begin{tabular}{|c|c|c|c|c|}
\hline Adjective & Description & $\begin{array}{l}\text { Derived G } \\
\text { Vertical } \\
\text { feet per }\end{array}$ & $\begin{array}{l}\text { ust Velocity } \\
\text { Horizontal } \\
\text { second }\end{array}$ & $\begin{array}{c}\text { Airspeed } \\
\text { Fluctuations } \\
\text { knots } \\
\end{array}$ \\
\hline Light & $\begin{array}{l}\text { A turbulent condition during } \\
\text { which occupants may be } \\
\text { required to use seat belts, } \\
\text { but objects in the aircraft } \\
\text { remain at rest. }\end{array}$ & $5-20$ & $5-9$ & $5-15$ \\
\hline Moderate & $\begin{array}{l}\text { A turbulent condition in } \\
\text { which occupants require } \\
\text { seat belts and occasionally } \\
\text { are thrown against the belt. } \\
\text { Unsecured objects in the } \\
\text { aircraft move about. }\end{array}$ & $20-35$ & $10-19$ & $15-25$ \\
\hline Severe & $\begin{array}{l}\text { A turbulent condition in } \\
\text { which the aircraft momen- } \\
\text { tarily may be out of control. } \\
\text { Occupants are thrown violent } \\
\text { against the belt and back intc } \\
\text { the seat. Objects not secure } \\
\text { in the aircraft are tossed ab }\end{array}$ & $\begin{array}{l}\quad 35-50 \\
\text { l. } \\
\text { ntly } \\
\text { to } \\
\text { red } \\
\text { bout. }\end{array}$ & $>20$ & more than 24 \\
\hline Extreme & $\begin{array}{l}\text { A rarely encountered turbu- } \\
\text { lent condition in which the } \\
\text { aircraft is violently tossed } \\
\text { about, and is practically } \\
\text { impossible to control. May } \\
\text { cause structural damage. }\end{array}$ & $\begin{array}{l}\text { over } 50 \\
y\end{array}$ & & $\begin{array}{l}\text { rapid fluctuations } \\
\text { over } 25\end{array}$ \\
\hline
\end{tabular}

Table 1. Turbulence criteria

other investigations had suggested a larger percentage for this smallest scale. Estoque [23] found a distribution of small patch sizes similar to Cunningham's results. Patches of larger dimensions are found less frequently and seem to be elongated in the direction of flow.

As suggested by the summary shown in Table 2 (Reiter [47]), the average vertical thicknesses of turbulent layers appear to lie between 


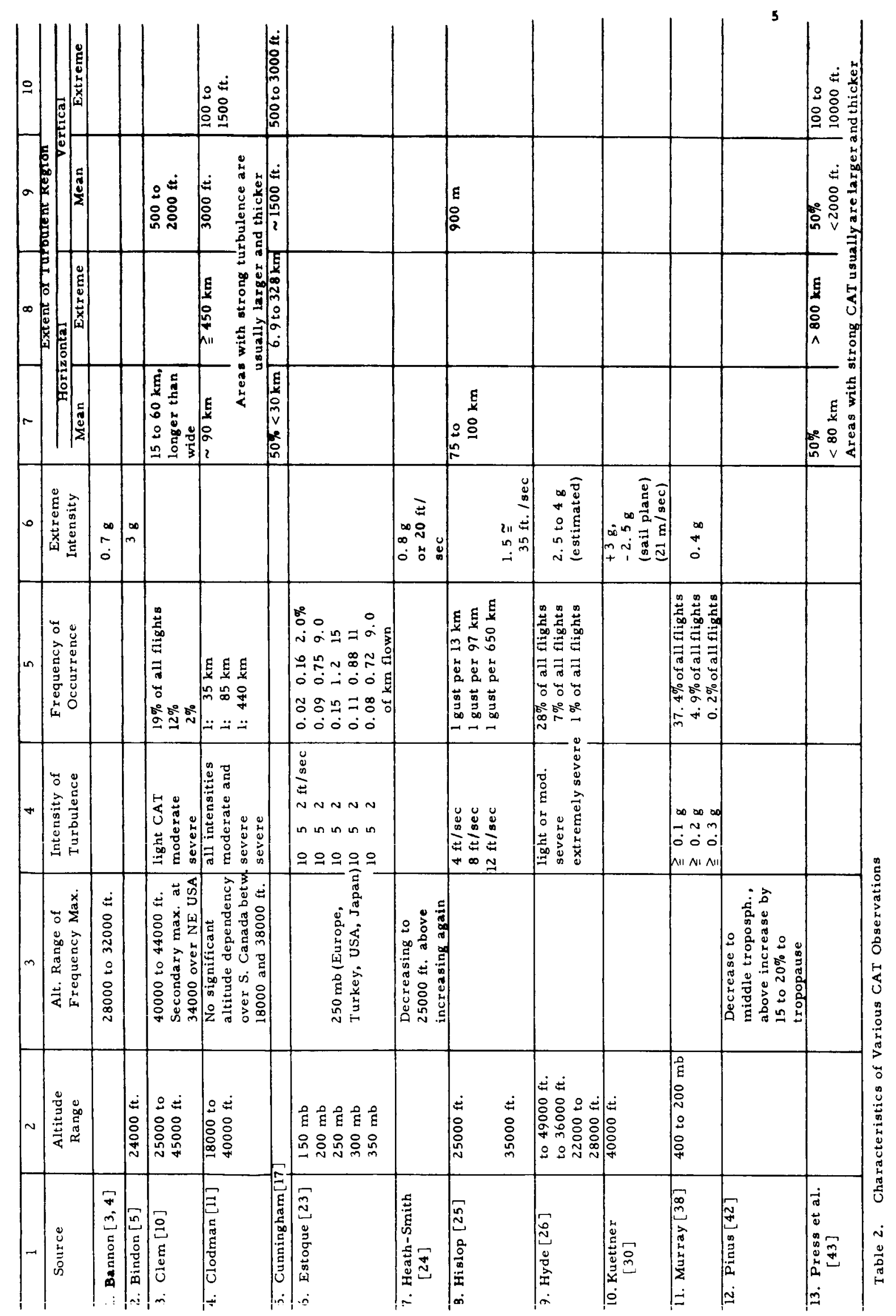


500 to 3000 feet. Clodman [11] reports an extreme case in which the turbulent layer extended over 15,000 feet. It is questionable, however, whether the turbulence was uniformly distributed, or consisted of a series of individual shallow turbulent layers with relatively quiescent intervening layers.

Frequency of occurrence statistics derived from turbulence encounters by aircraft depend upon season, location, type of aircraft, flight planning procedures, and the degree of subjectivity of the reports. Some of the results from early investigations are summarized in Table 2 . Clodman, Morgan and Ball [1 12 ] have concluded that $3 \%$ of flight time over continental areas between 20,000 to 45,000 feet will be in turbulence. Of the $3 \%$ total, light turbulence may be expected $75 \%$ of the time, moderate 15-20\%, severe 5-10\% and extreme 1-3\%. A somewhat larger percentage was found by Briggs and Roach [6]. Slight intensity was found $5.4 \%$ of flying time, moderate $4.0 \%$, and severe $0.2 \%$. Endlich and McLean [18] found a comparable result. Endlich [20] found CAT about $12 \%$ of the time. Of this, $2.5 \%$ was moderate and $0.2 \%$ was severe. Endlich and McLean [21] have determined the average distribution of light or greater intensity with respect to the jet stream core. As shown in Fig. 2, the greatest frequency is on the cyclonic side of the core, as noted by a number of investigators.

An idealized jet stream model cross section is shown in Fig. 3, after Endlich and McLean [18]. More complex models have been presented, for example, by Brundidge and Goldman [8] and Serebreny, Wiegman and 


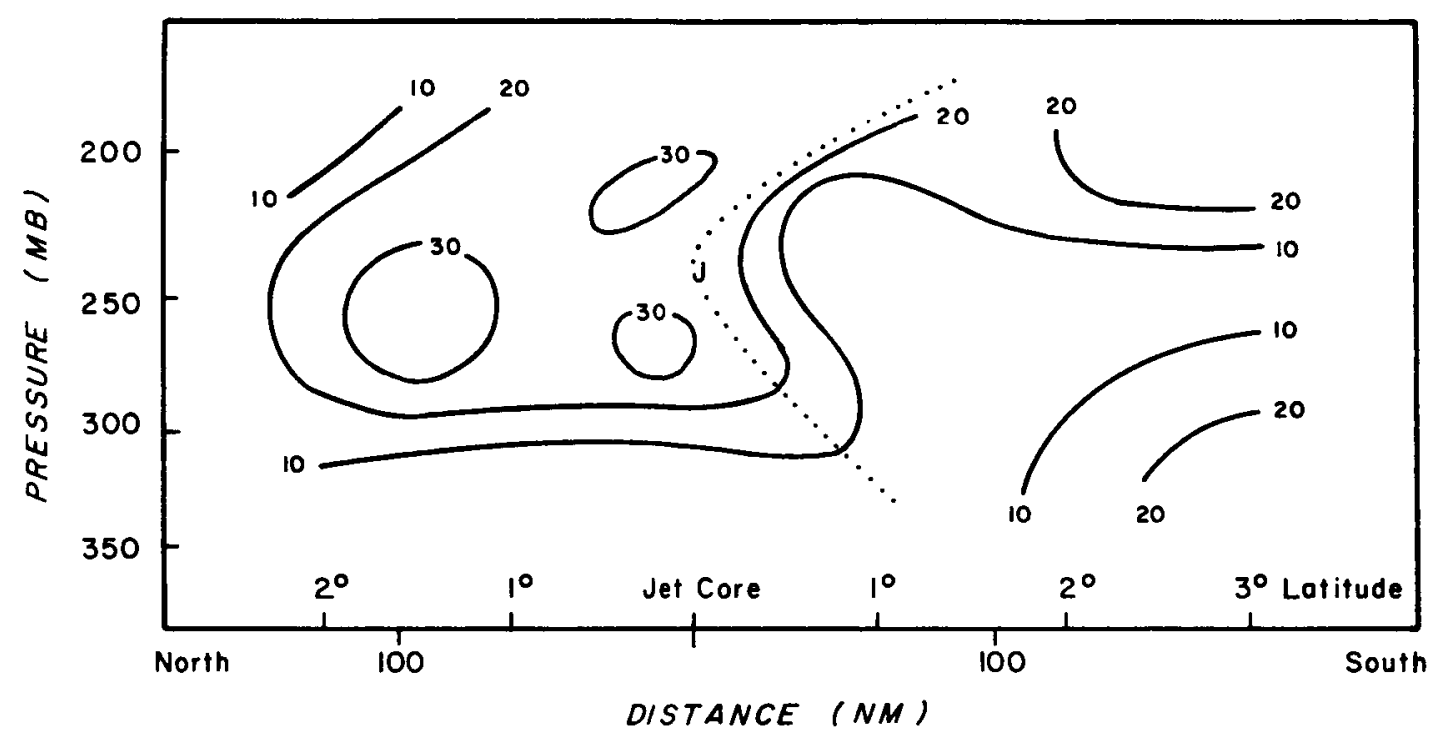

FIG. 2. AVERAGE DISTRIBUTION OF PER CENT OF TIME TURBULENCE OF LIGHT OR GREATER INTENSITY IS ENCOUNTERED IN THE JET STREAM. (after Endlich and McLean (21 J). 


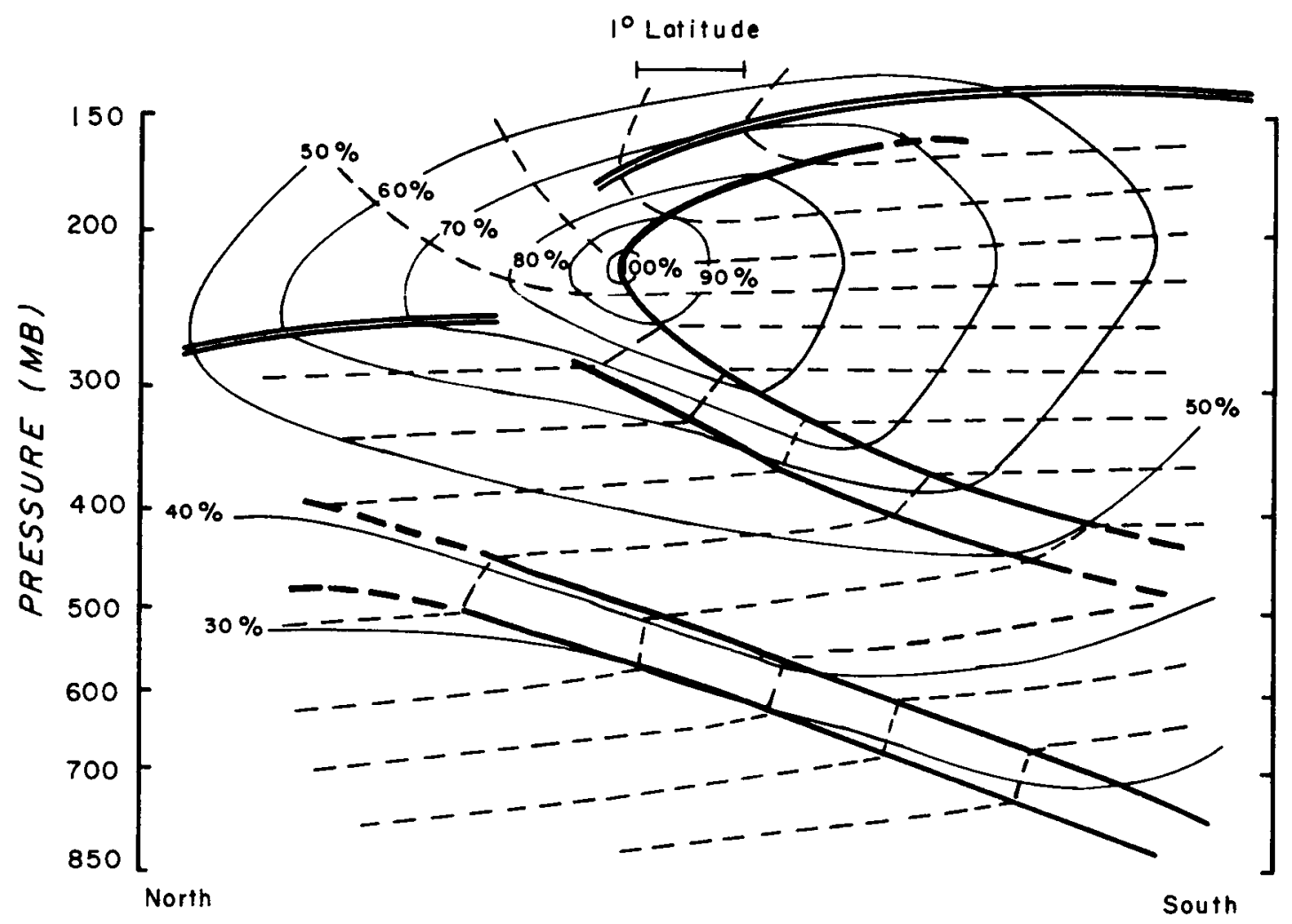

FIG. 3. IDEALIZED JET STREAM MODEL CROSS SECTION. ISOTACHS (\% OF CORE SPEED) DENOTED BY THE SOLIO LINE (-), DASHEO LINES (-- -), ARE SCHEMATIC ISOTHERMS. STABLE LAYERS ARE INDICATED BY THICK SOLID LINES (—), ANO DOUBLE LINES, ( SUBTROPICAL TROPOPAUSES. (ofter Endlich and MCLean [18]) 
Hadfield [57], the latter indicative of those proposed by Canadian workers. While the Endlich and McLean model is somewhat simplified and indicative only of the polar front jet, it does contain the stable, baroclinic zone (jet stream front). The polar front has been placed arbitrarily such that it intersects the $500-\mathrm{mb}$ surface below the jet core. The core placement with respect to the jet stream front and the tropopause break may be too far north.

The distributions of CAT with respect to schematic cross sections taken through trough, ridge and straight flow conditions are shown in Fig. 4 after Endlich [19]. These show a tendency for moderate to severe CAT occurrence on the upper boundary of the jet stream front and on the sub-tropical tropopause.

Any anticipation of CAT encounters should consider topographical effects. A schematic mountain wave flow regime is shown in Fig. 5, after Jenkins $[27]$. Turbulence is to be expected in the rotor circulation and in layers (not shown) where the wave motion leads to a maximum wind shear. The indicated turbulent layer at the tropopause is misleading as to the extent of turbulence.

Mountain wave behavior is largely governed by the Lyra [34] parameter: ${ }^{3}$

$$
\ell^{2}=\frac{g}{\theta u^{2}} \frac{\partial \theta}{\partial z}
$$

\footnotetext{
${ }^{3}$ The Scorer [56] parameter differs by a wind profile curvature term that is difficuit to evaluate.
} 


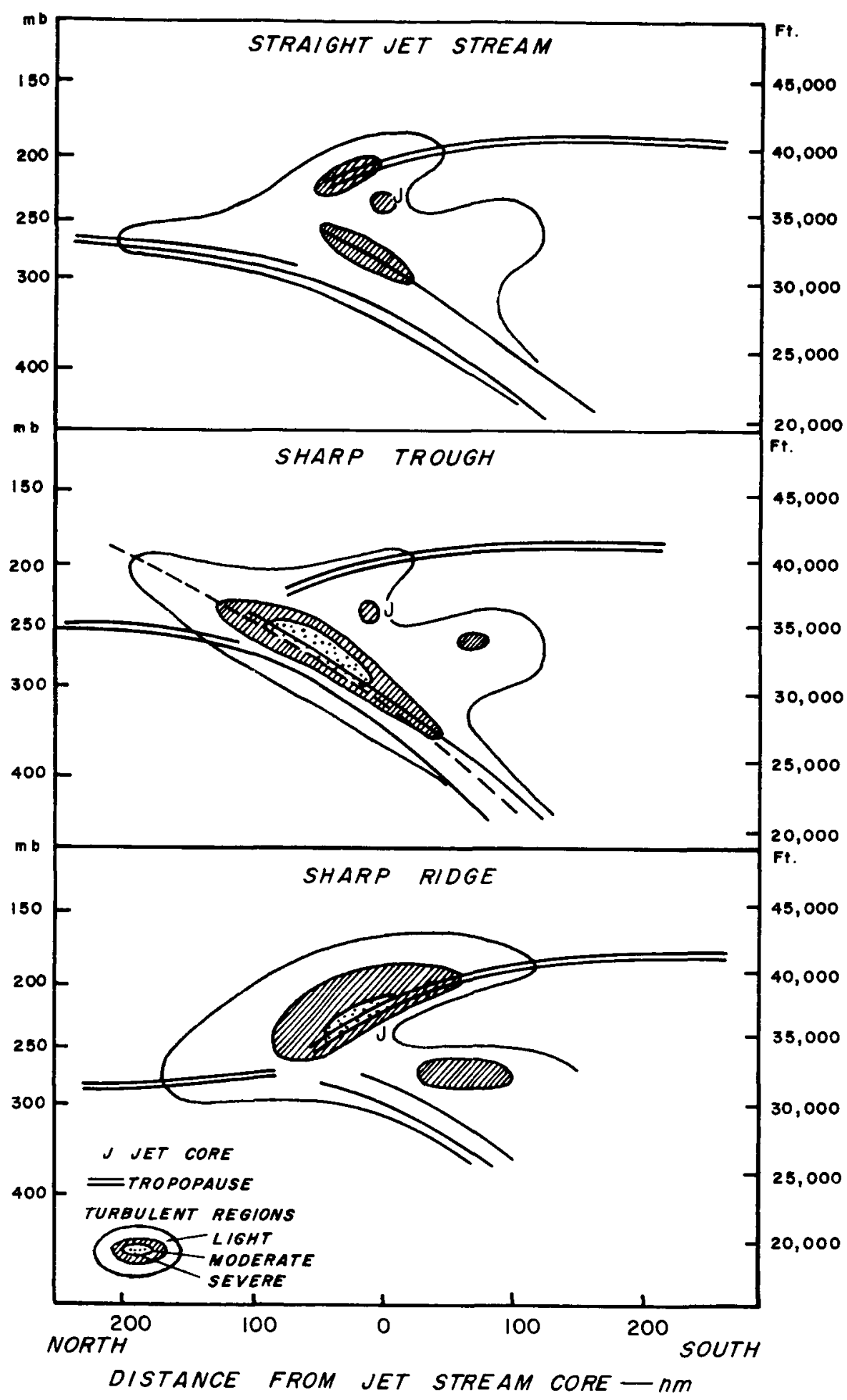

FIG.4. IDEALIZED MODELS OF TURBULENT REGIONS IN THE VICINITY OF THE JET STREAM (after Endlich [19] ) 


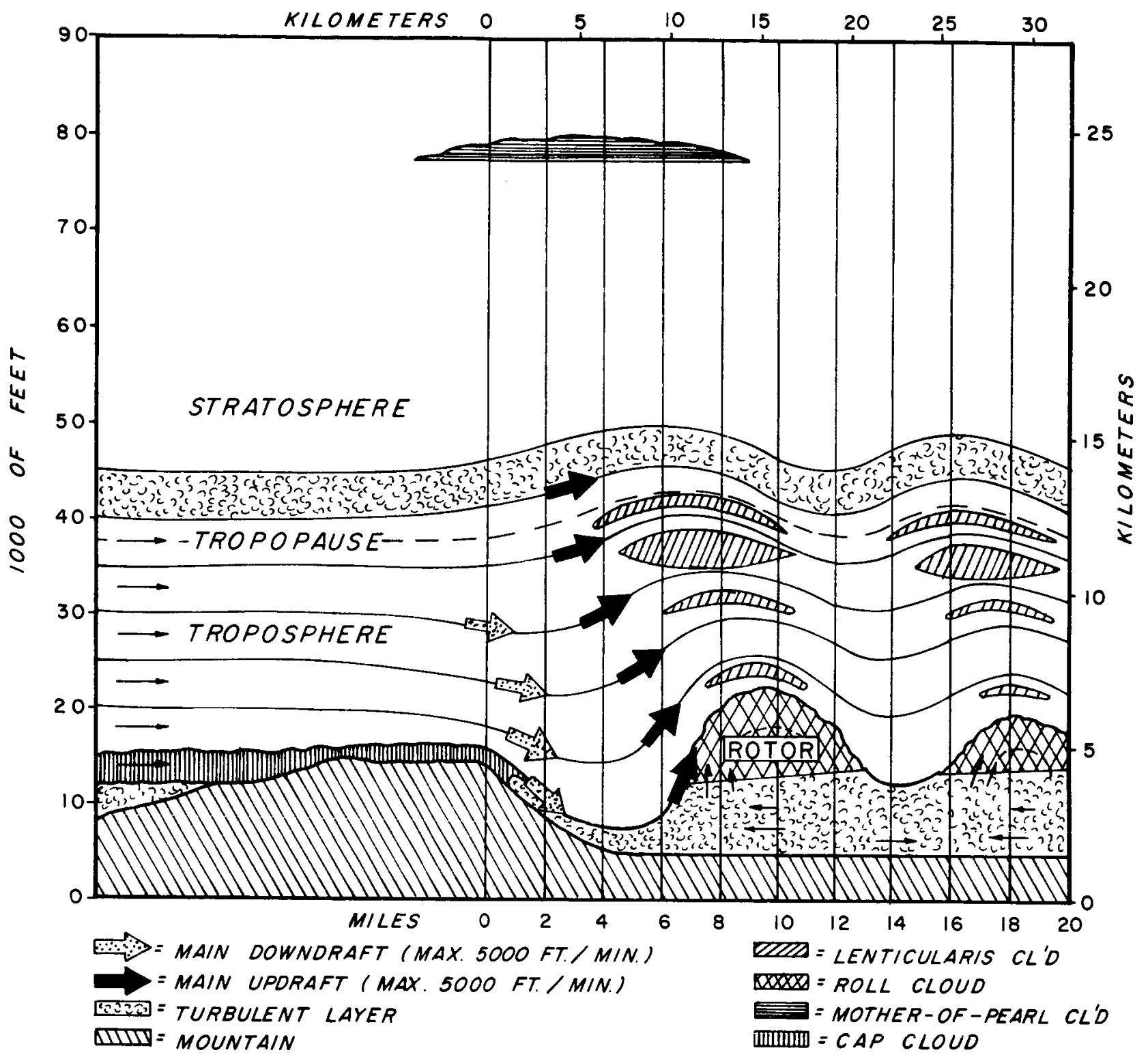

FIG. 5. CROSS SECTION OF CONDITIONS ASSOCIATED WITH A TYPICAL MOUNTAIN WAVE.

( after Jenkins [27]) 
where $\ell$ is the wave number generated in the lee of the mountain, $g$ is the acceleration of gravity, $\theta$ is potential temperature, and $u$ is wind speed component normal to the mountain range. The vertical coordinate is denoted by $z$. In a case study, Reiter [48] has shown that an aircraft loss in otherwise minimal turbulence conditions was likely due to a mountain wave phenomenon. The Lyra parameter decreased to the lower boundary of the stable baroclinic zone where it increased to a secondary maximum, a favorable condition for the formation of lee waves.

A cloud photogrammetric study by Reiter and Nania [49] has shown that both standing and traveling gravity waves ranging from 100 meters to 50 kilometers are found at jet stream levels in the lee of the Rocky Mountains. The shorter waves are in the range of clear-air turbulence. Similar scales were found by Conover [16].

Even moderate terrain relief can have a pronounced effect on CAT frequencies. In a study of CAT occurrences in the lee of the small ridge shown in Fig. 6, Clodman, Morgan and Ball [12] found an enhanced frequency of occurrence (Fig. 7) when the $850-\mathrm{mb}$ flow was approximately normal to the ridge and a reduction (Fig. 8) when the flow was parallel. Further, the enhancement was favored by large low-level wind speeds and small wind shear in the middle troposphere. The enhancement under mountain-wave conditions is also reflected in the statistics compiled by Colson $[13,14]$. 


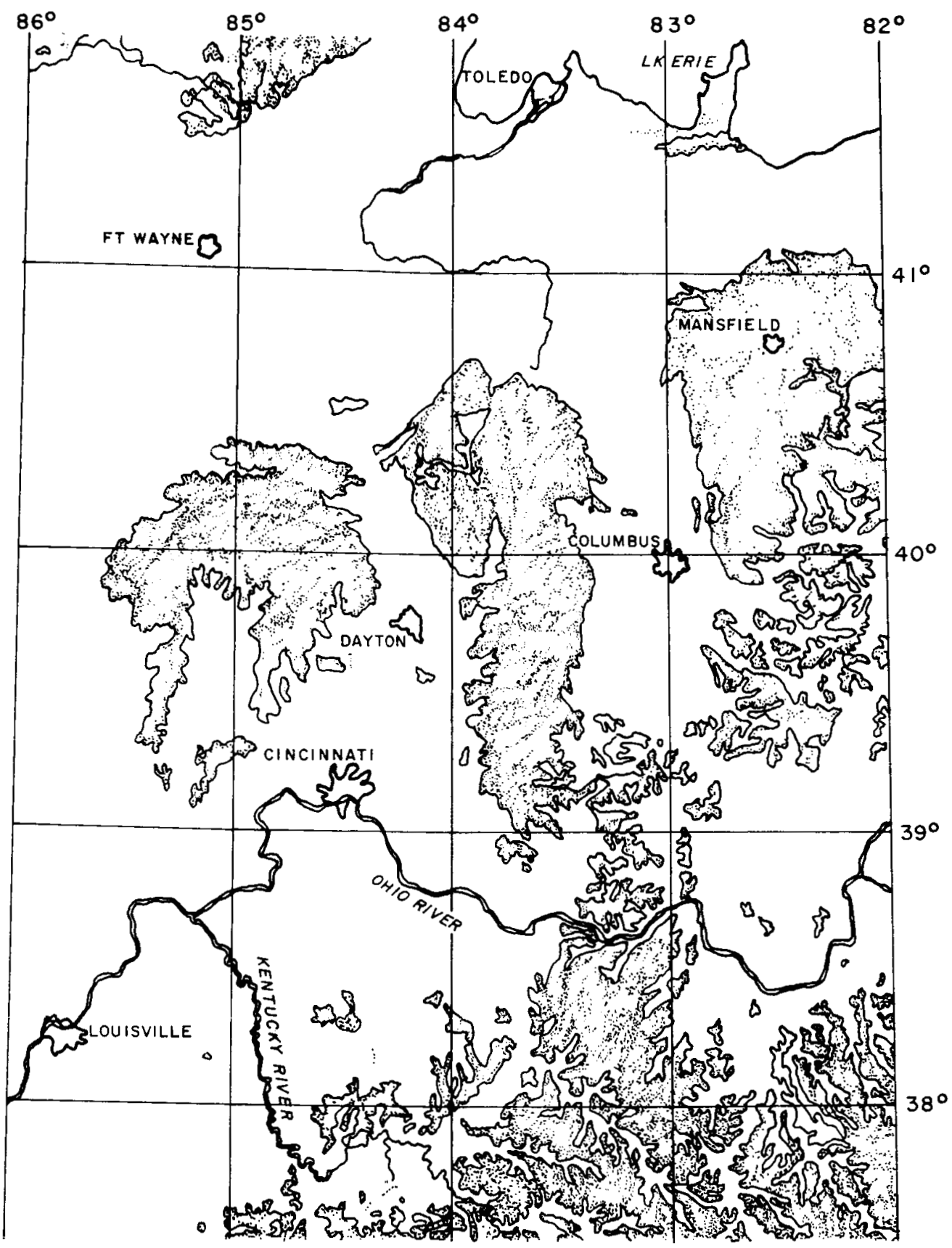

FIG.6. TOPOGRAPHY IN VICINITY OF PATTERSON AFB. UNSHADED AREAS O-1000 FT. MSL; SHADED AREAS $1000-2000$ FT. MSL. 


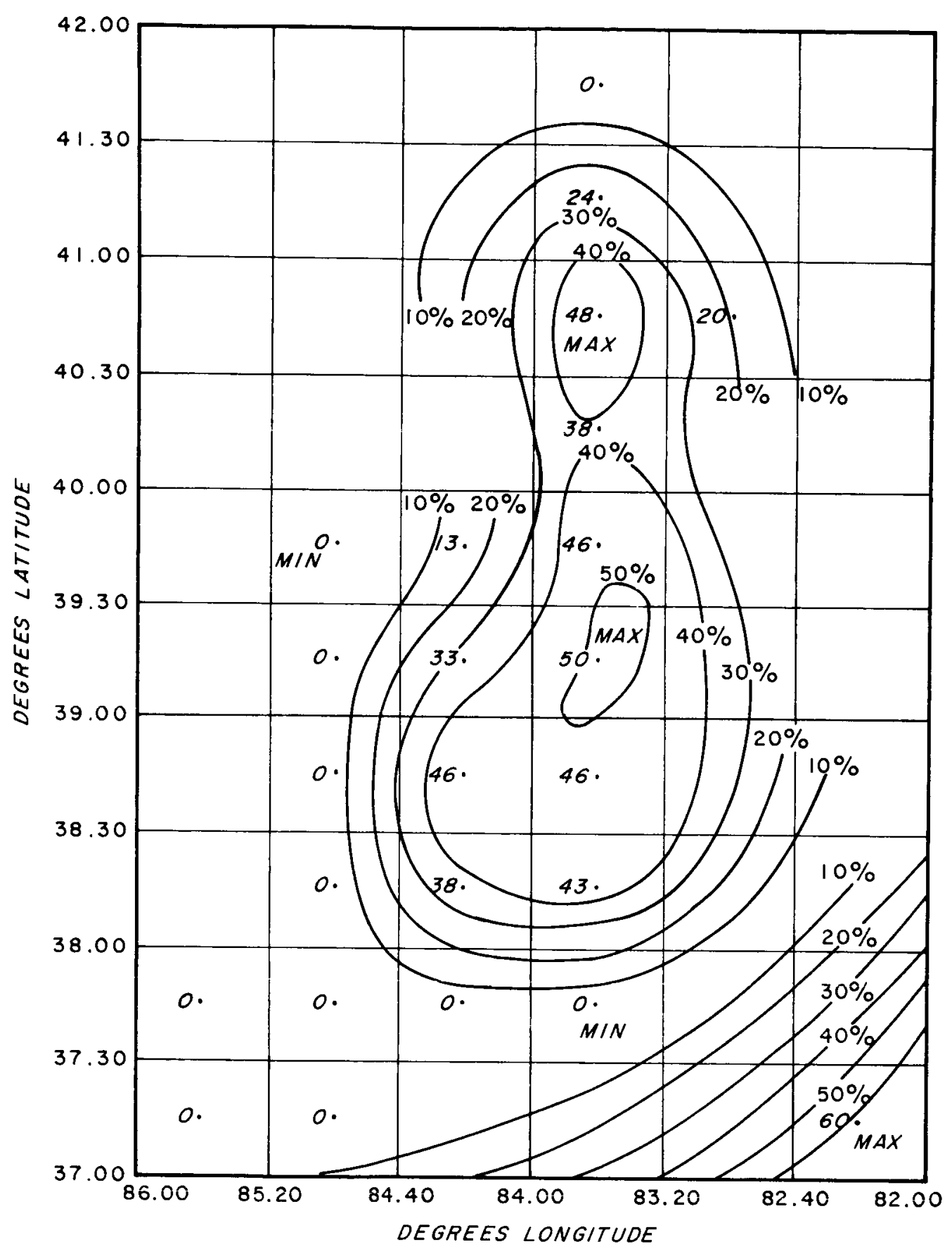

FIG. 7. PERCENTAGE OF TURBULENCE OCCURRENCES IN THE PATTERSON AREA WITH THE $850 \mathrm{MB}$ CENTRAL WIND DIRECTION $\left(085-265^{\circ} \pm 30^{\circ}\right)$ NORMAL TO THE CENTRAL RIDGE. 


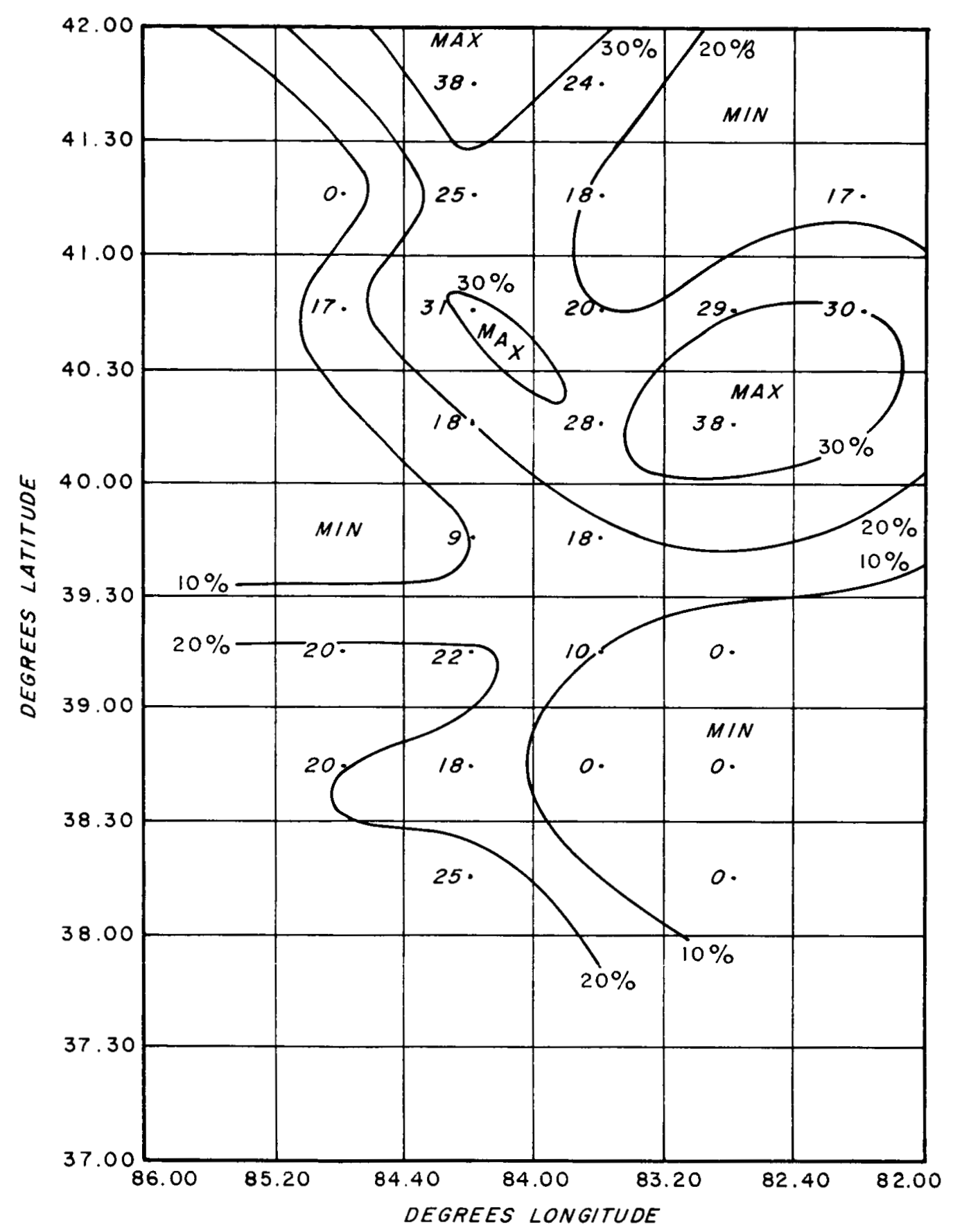

FIG.8. PERCENTAGE OF TURBULENCE OCCURRENCES IN THE PAT TERSON AREA WITH THE $850 \mathrm{MB}$ CENTRAL WIND DIRECTION $\left(175-355^{\circ} \pm 59^{\circ}\right)$ PARALLEL TO THE CENTRAL RIDGE. 
Finally, Clodman, Morgan and Ball [12] have shown that turbulence encounters over oceanic areas are an order of magnitude smaller $(0.24 \%)$ than over continental areas.

\section{MECHANISM, SIGNATURE AND STRUCTURE OF CAT}

Turbulent fluctuations stemming from Reynolds stresses associated with a mean wind shear must work against the stabilizing effect of gravity. Richardson's well-known stability criterion asserts that turbulence can proceed only if turbulent generation exceeds the work against gravity. Thus, the flux Richardson number,

$$
R_{f}=\frac{K_{h}}{K_{m}} \frac{\frac{g}{\theta} \frac{\partial \theta}{\partial z}}{\left(\frac{\partial \bar{u}_{i}}{\partial z}\right)^{2}},
$$

must be less than unity for the continuation of turbulence. Here $\vec{u}$ is the mean fluid velocity and $K_{h}$ and $K_{m}$ are the eddy diffusivities for heat and momentum, respectively. A summation convention is implied for the shear tensor, $\partial \bar{u}_{i} / \partial x_{j}$.

As discussed by Lumley and Panofsky[33], the diffusivity ratio $\left(\mathrm{K}_{\mathrm{h}} / \mathrm{K}_{\mathrm{m}}\right)$ is near unity for unstable stratification, but may decrease with increasing stability. The gradient Richardson number (=1/Froude number $)$ is obtained by multiplying $R_{f}$ by the turbulent Prandtl number:

$$
R_{i}=\left(\frac{K_{h}}{K_{m}}\right) R_{f} .
$$


It is the gradient Richardson number that has been used with mixed success in correlation studies with CAT. Brundidge [7], Lake [31] and Reiter [45], as examples, found poor correlation between $R_{i}$ and CAT. Anderson [1], Rustenbeck [53] and Kronebach [29] found some correlation. Petterssen and Swinbank [41] found that the Richardson criterion was applicable in the free atmosphere provided that $\mathrm{K}_{\mathrm{h}} / \mathrm{K}_{\mathrm{m}} \sim 0.65$. The disparity in results may be attributable to the vertical grid coarseness in the $R_{i}$-calculations.

Other criteria have been developed. Radok and Clarke [44] have given a modified (thermal) Richardson number. Sasaki [54] has derived a criterion involving wind and temperature curvatures for a three-layer model. The latter appears to be superior to the Richardson criterion for CAT, but suffers from the necessity of determining second vertical differences.

Other parameters have been studied with mixed or little success. Considerations of the stability, $\frac{\mathrm{g}}{\theta} \partial \theta / \partial z$, alone have met with little success. The vertical wind shear has been suggested by some investigators as superior to the Richardson number. Also, a turbulence index (Endlich and Mancuso [22]), $\left|u \frac{\partial a}{\partial z} \frac{\partial^{2} T}{\partial z}\right|$, where $a$ is wind direction and $T$ is absolute temperature, was found to be as skillful as $R_{i}$ in identifying turbulent regions. The horizontal shear has also been examined, again with mixed results. A study of two confluent jet streams by Reiter and Nania [49] has shown that the vector wind shear should be considered. 
This is in accord with the results of Endlich and Mancuso [22], and the suggestions by Keitz [28] and Schwerdtfeger and Radok [55], except that the pertinent differential advection in the first study appears to be in the sense of atmospheric stabilization.

The criteria above are not scale-dependent. Since moderate and severe CAT appears to occur preferentially on the upper boundary of thermally stable layers, an appropriate consideration is the critical wavelength, $\lambda_{c}$, of gravitational shearing (Helmholtz) waves on the interface between two stably stratified, incompressible fluids (Reiter [47, 50]):

$$
\lambda_{c}=\frac{2 \pi}{g} \frac{\left(u_{o}-u_{1}\right)^{2} T_{o} T_{1}}{\left(T_{1}+T_{o}\right)\left(T_{1}-T_{o}\right)}
$$

where the subscripts 0 and 1 refer to the lower and upper layers, respectively. Wavelengths less than $\lambda_{c}$ are unstable. This is indicated schematically in Fig. 9. The large black arrows denote the wind vectors in the two layers. The gravity wave crests are normal to the vector shear. Small black arrows indicate vertical motion. Such gravity waves may be excited, for example, as lee waves. The wind shear necessary to produce certain critical wave lengths is shown in Table 3 for various temperature discontinuities (Reiter [50]). The value of $\lambda_{c}$ will be reduced for finite transition layers, but the range of wavelengths can easily fall within the CAT spectrum input region. 


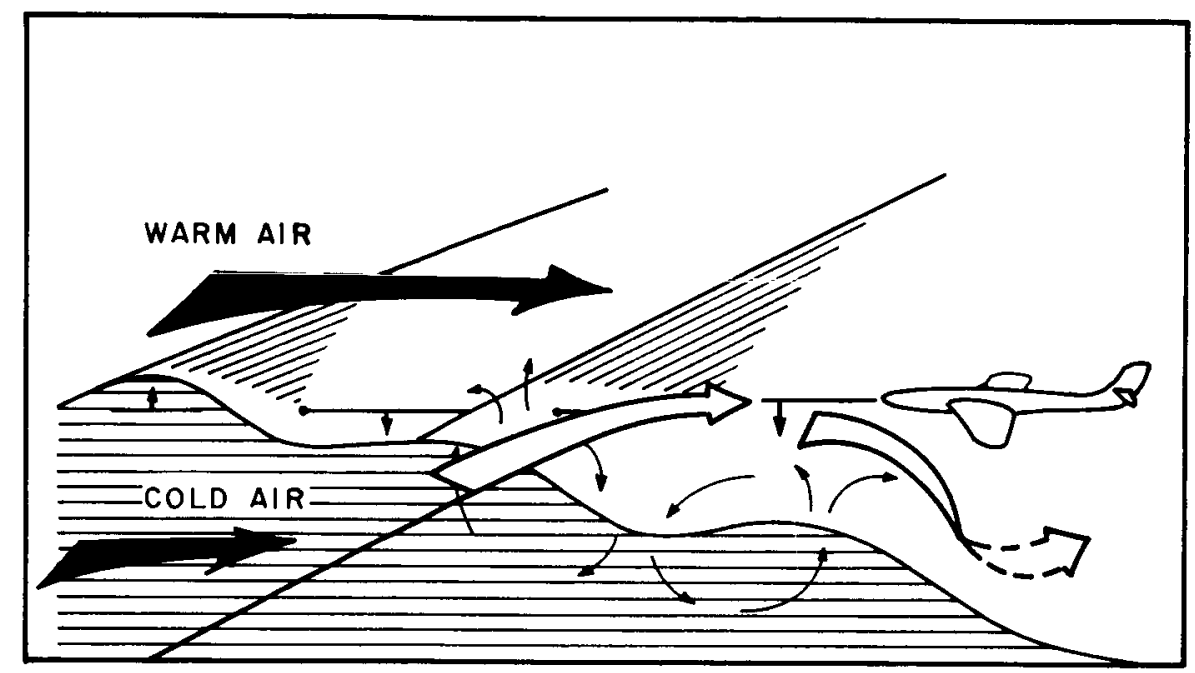

FIG. 9. SCHEMATIC DIAGRAM OF AIR FLOW IN THE VICINITY OF AN IDEALIZED GRAVITATIONAL SHEARING WAVE ladapted from Reiter [5/]) 


\begin{tabular}{cccc}
\hline$\Delta \mathrm{T}\left({ }^{\circ} \mathrm{C}\right)$ & $\lambda_{\mathrm{c}}=200 \mathrm{~m}$ & $\lambda_{\mathrm{c}}=100 \mathrm{~m}$ & $\lambda_{\mathrm{c}}=50 \mathrm{~m}$ \\
\hline 2 & $2.3 \mathrm{~m} \mathrm{sec}^{-1}$ & 1.6 & 1.2 \\
4 & 3.3 & 2.3 & 1.6 \\
6 & 4.0 & 2.9 & 2.0 \\
10 & 4.7 & 3.3 & 2.3 \\
\hline
\end{tabular}

Table 3. Vertical wind shear for different temperature discontinuities and critical wave lengths at an interface.

The argument for the "breaking" of gravitational shearing waves as the energy source for CAT may be substantiated by an examination of mechanical energy spectra such as shown by Reiter and Burns [52]. Smoothed spectra of the u-, v- and w-components (along flight direction, transverse and vertical, respectively) are shown in Fig. 10 (after Burns and Rider [9]) for moderate to severe CAT. Since the same turbulence patch was studied for both the headwind and transverse measurements, Reiter and Burns [52] have argued that a wave phenomenon of specific orientation was responsible for the energy input at wavelengths corresponding to the "hump" in the spectra. 


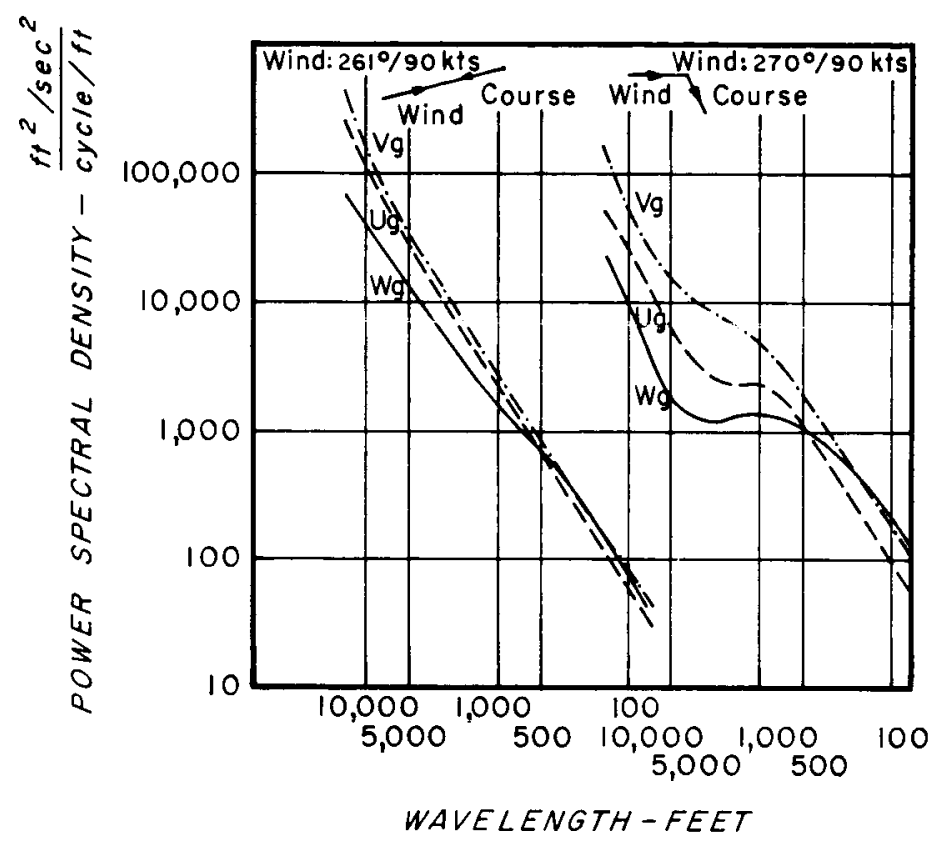

FIG. I0. "SMOOTHED" SPECTRA OF $u-, v-$, AND $w-$ COMPONENTS OF TURBULENCE MEASURED DURING FLIGHTS 18B AND 18D (after Burns and Rider, 1965 [9]). 


\section{REFRACTIVE INDEX SPECTRA}

Estimates of the scattering from atmospheric turbulent fluctuations require an evaluation of the spectral density of refractive index at a wave number $4 \pi \sin \left(\frac{\theta}{2}\right) / \lambda$, where $\theta$ is the scattering angle and $\lambda$ is the wave length of the radiation. For backscattering $(\theta=\pi)$ this is twice the radian wave number associated with the incident radiation. As suggested schematically in Fig. 11, the scattering cross section is determined by a narrow band filter acting on the refractive index spectrum. The filtered evaluation has been placed near the dissipation subrange boundary. The implications are discussed below.

Following Tatarski[61], the fluctuation spectrum for the refractive index will be approached by considering conservative passive additives, say $X(\vec{r})$, where $\vec{r}$ is a position vector. Although $X$ will ultimately be taken as the potential refractivity, fluctuations in refractive index near the tropopause are due primarily to temperature variations and considerations for temperature spectra will be used as guidelines. In the considerations that follow, the Reynolds ${ }^{4}$ and Péclet ${ }^{5,6}$ numbers are taken to be large so that a convective subrange exists where the pertinent outer scale,

\footnotetext{
4 The dimensionless ratio of measures of inertia to viscous forces, $R_{e}$.

5 The dimensionless ratio of convective to molecular flux of heat, $P$. The Péclet and Reynolds numbers are related by $P=\sigma R_{e}$, where $\sigma(=\nu / x)$ is the Prandtl number, the ratio of molecular momentum diffusivity to thermal diffusivity.

6

A more appropriate number would be $s R_{e}$, where $s\left(=\nu / \nu_{x}\right)$ is the Schmidt number, the ratio of molecular momentum diffusivity tu $x$-diffusivitity.
} 


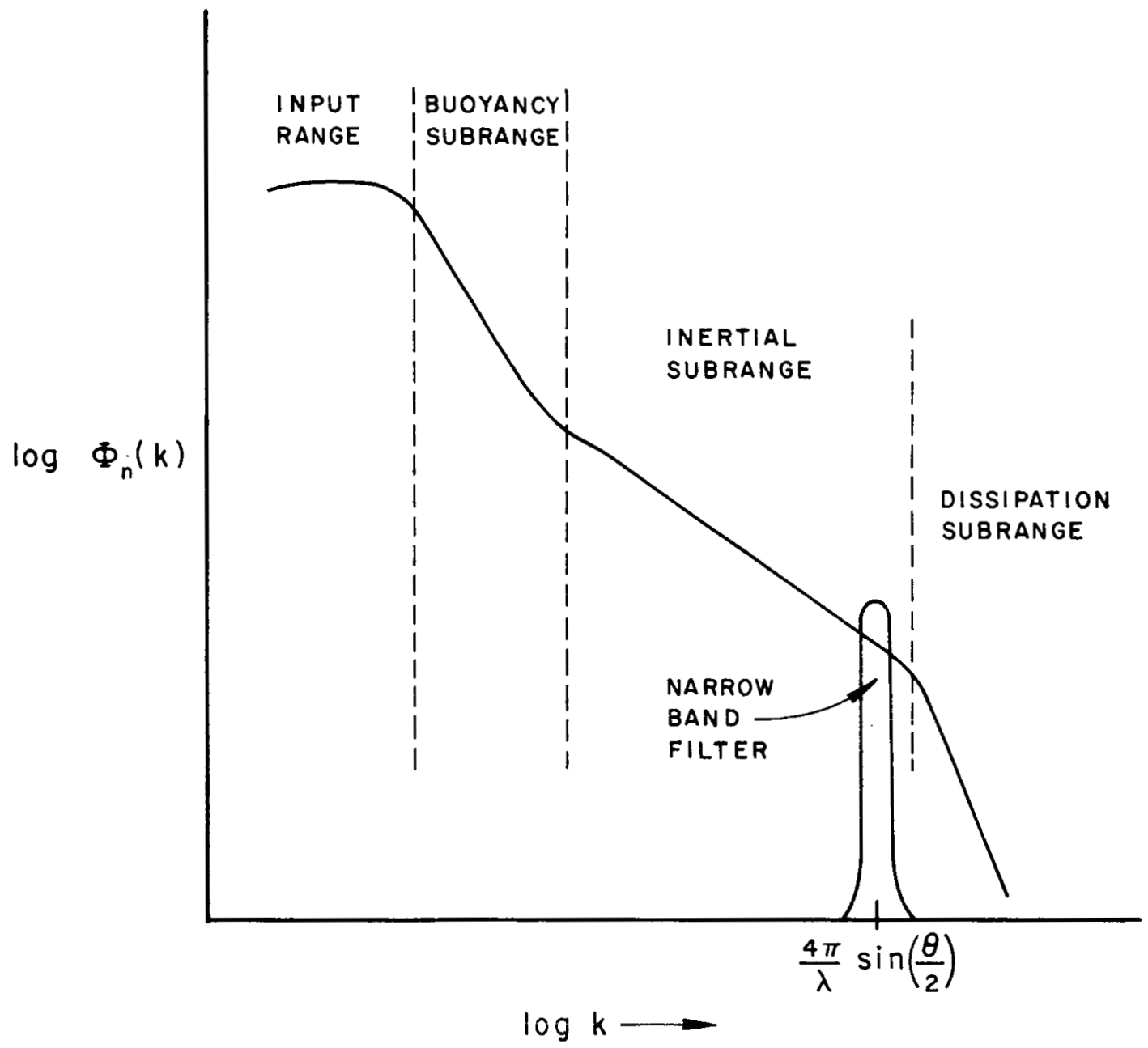

FIG. II. SCHEMATIC REFRACTIVE INDEX SPECTRUM AS A FUNCTION OF WAVE NUMBER INDICATING TYPICAL RANGES AND THE NARROW BAND FILTER WHICH DETERMINES SCATTERING FROM TURBULENT FLUCTUATIONS (adapted from Staras and Wheelon [58]) 
$L_{x}$, and the diffusive inner scale, $l_{x}$, are such that $L_{x} \gg \gg l_{x}$.

In a locally isotropic random field the structure function

$$
D_{x}\left(\left|\vec{r}_{1}-\vec{r}_{2}\right|\right)=\overline{\left[x\left(\vec{r}_{1}\right)-X\left(\vec{r}_{2}\right)\right]^{2}} \text { ensemble }
$$

then depends only upon $r\left(=\left|\vec{r}_{1}-\vec{r}_{2}\right|\right), \eta$ and $\varepsilon$ where $\eta$ represents the amount of inhomogeneity which disappears per unit time due to molecular diffusion and $\epsilon$ is the energy dissipation rate. In this convective, inertial subrange dimensional considerations show that

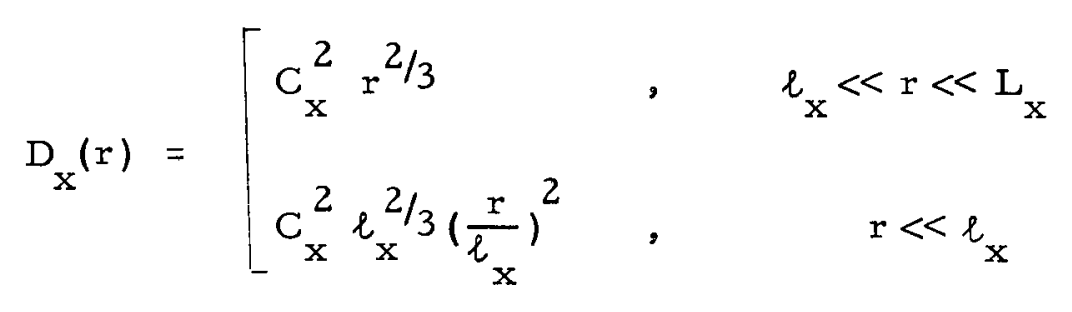

where

$$
C_{x}^{2}=a^{2} \eta \epsilon^{-1 / 3}
$$

Here the parameter $a^{2}$ depends upon the Richardson number for stable stratification. The inner and outer scales are given by Tatarski as

$$
l_{x}=\left(27 a^{6} \nu_{x}^{3} / \epsilon\right)^{1 / 4}
$$

and

$$
L_{x}=\left(K_{x} /\left|\left(\partial \bar{u}_{i} / \partial x_{j}\right)\right|\right)^{1 / 2}
$$

where $\nu_{x}$ is the molecular diffusion coefficient for $X$ and $K_{X}$ is the coefficient of turbulent diffusion of $X$ (Tatarski takes this as the 
momentum coefficient). Here the inner scale is found as the point of intersection of the asymptotic expansions of eqs. $4.2(\mathrm{a})$ and $4.2(\mathrm{~b})$.

The rate of molecular dissipation of $\mathrm{x}$-fluctuations is given by

$$
\eta=\nu_{x} \overline{\left(\operatorname{grad} X^{\prime}\right)^{2}}=K_{x}(\operatorname{grad} \bar{X})^{2}
$$

The energy dissipation rate is

$$
\epsilon=K_{m}\left(\partial \bar{u}_{i} / \partial x_{j}\right)^{2}
$$

The three-dimensional spectral density corresponding to $(4.2)$ is

$$
\Phi_{x}(k)=\frac{\Gamma\left(\frac{8}{3}\right) \sin \left(\frac{\pi}{3}\right)}{4 \pi^{2}} C_{x}^{2} k^{-11 / 3}
$$

where $k$ is radian wave number $(2 \pi / \lambda)$. Here it will be convenient to use the one-dimensional counterpart which may be defined by

$$
\Phi_{x}(k)=-\frac{1}{2 \pi k} \frac{d F_{x}(k)}{d k}
$$

or

$$
F_{x}\left(k_{1}\right)=-2 \pi \int_{-\infty}^{k} k_{x}(k) d k
$$

Thus,

$$
F_{x}(k)=\frac{3}{10 \pi} \Gamma\left(\frac{8}{3}\right) \sin \left(\frac{\pi}{3}\right) C_{x}^{2} k^{-5 / 3}
$$

Equations (4.3) and (4.6) may be used to write

$$
F_{X}(k)=\frac{a^{2}}{2 \pi} \Gamma\left(\frac{5}{3}\right) \sin \left(\frac{\pi}{3}\right) K_{x}(\operatorname{grad} \bar{X})^{2} \epsilon^{-1 / 3} k^{-5 / 3} .
$$


The critical part of this study is the determination of a stable form for $F_{x}(k)$; that is, a form which lends itself to evaluation from experimental data, but with minimal uncertainty. Equation (4.12) is not wellsuited for this purpose since the parameters involved range over several orders of magnitude. Atlas, Hardy and Naito [2] have introduced the outer scale explicitly. In the present instance this would be by ${ }^{7}$

$$
C_{x}^{2}=a^{2} L_{x}^{4 / 3}(\operatorname{grad} \bar{x})^{2}
$$

and

$$
F_{x}(k)=\frac{a^{2}}{2 \pi} \Gamma\left(\frac{5}{3}\right) \sin \left(\frac{\pi}{3}\right) L_{x}^{4 / 3}(\operatorname{grad} \bar{x})^{2} k^{-5 / 3}
$$

Since stable stratification will be presumed for the considerations here, $a^{2}=a^{2}\left(R_{i}\right)$. Data presented by Lumley and Panofsky $[33$, p. 204$]$, adapted from Tatarski [61], indicate that $\mathrm{a}^{2}$ decreases with increasing $R_{i}$. Tatarski $[60]$ has concluded from a somewhat sparse data sample that

$$
a^{2}=0.1 / R_{i}
$$

for $R_{i}$ greater than about 0.05 . The uncertainty in $L_{x}^{4 / 3}$ is one order of magnitude. The range of $|\operatorname{grad} \bar{X}|$ is of the order of a factor of ten. Although it would seem that these uncertainties would be resolved by evaluation from experimental data, the scale of observing is usually too

\footnotetext{
7 This presumes equality of the diffusivities, $\mathrm{K}_{\mathrm{x}}$ and $\mathrm{K}_{\mathrm{m}}$.
} 
large for an appropriate determination of gradients and Richardson's number.

Again following Atlas, Hardy and Naito [2], since the object here is to evaluate the refractive index spectrum in the presence of clear-air turbulence, it is appropriate to introduce some measure of the mechanical energy. The one-dimensional mechanical energy spectrum in the inertial subrange is

$$
E(k)=c \frac{\Gamma\left(\frac{5}{3}\right) \sin \left(\frac{\pi}{3}\right)}{2 \pi} \varepsilon^{2 / 3} k^{-5 / 3},
$$

where $\mathrm{c}$ is a numerical constant. If the spectral density is defined by

$$
\int_{0}^{\infty} E(k) d k=\overline{\left(u^{\prime}\right)^{2}}
$$

where $u^{\prime}$ is the longitudinal velocity fluctuation, then $c \doteq 4$ for $k=2 \pi / \lambda$ (Panofsky and Pasquill[39]). The constant for transverse components is larger by a factor of $4 / 3$.

Equation (4.16) is presumed to be valid only for lag separations, $\ell_{\mathrm{m}} \ll \mathrm{r} \ll \mathrm{L}_{\mathrm{m}}$, where(Tatarski $\left.[61]\right)$

$$
\ell_{m}=\left\{(15 c \nu)^{3} / \epsilon\right\}^{1 / 4}
$$

and $\mathrm{L}_{\mathrm{m}}$ differs from $\mathrm{L}_{\mathrm{x}}$ by the replacement $\mathrm{K}_{\mathrm{x}} \rightarrow^{-} \mathrm{K}_{\mathrm{m}}$. That is, the outer scales for momentum and the X-quantity are related by

$$
\mathrm{L}_{\mathrm{m}} / \mathrm{L}_{\mathrm{x}}=\mathrm{s}_{*}^{1 / 2}
$$

where $s_{*}$ is the turbulent Schmidt number. 
A more critical factor in the consideration of overlapping of the inertial subranges are the microscales. For temperature and momentum the microscales are related by

$$
\frac{\ell_{\mathrm{m}}}{l_{\mathrm{T}}}=\sigma^{3 / 4} \text {. }
$$

The Prandt 1 number is 0.7 for the atmosphere so that

$$
\ell_{\mathrm{T}} \doteq 1.31 \ell_{\mathrm{m}}
$$

Tatarski's microscale for momentum is [eq. (4.18)]

$$
l_{\mathrm{m}_{1}}=4.54\left(\frac{\nu^{3}}{\epsilon}\right)^{1 / 4}
$$

This is not substantially different from the estimate by Megaw [37] used by Atlas, Hardy and Naito [2]. Pao [40] has indicated that the microscale for the convective subrange for arbitrary Schmidt number is

$$
l_{x}=\left(\frac{\nu_{x}^{3}}{\epsilon}\right)^{1 / 4} \text {. }
$$

This differs from Tatarski's estimate by a factor $2.28 \mathrm{a}^{3 / 2}$. For small Richardson number, this is of the order of 3.8. Thus, using either Tatarski's or Pao's results

$$
l_{x}=l_{m} s^{-3 / 4}
$$

where $\mathbf{s}$ is the Schmidt number. As determined by Atlas, Hardy and Naito [2], the microscale iir clear-air turbulence fin the jet stream 
vicinity) is of the order of a few millimeters. According to their classification, moderate clear-air turbulence corresponds to an energy dissipation rate of the order of $100 \mathrm{~cm}^{2} \mathrm{sec}^{-3}$. Temperature spectra taken by Lowenberg, Bostick and McCullough [32] show definite slope discontinuities at a scale of the order of $10 \mathrm{~cm} .^{8}$ If the average value of $\epsilon(100 \mathrm{~m})$ given by Wilkins [62] is used, then (using 4.23 )

$$
\ell_{T}=\left\{\frac{\left(0.19 \mathrm{~cm}^{2} \mathrm{sec}^{-1}\right)^{3}}{2 \mathrm{~cm}^{2} \mathrm{sec}^{-3}}\right\}^{1 / 4}=2.4 \mathrm{~mm}
$$

Using Tatarski's estimate, $\ell_{T} \approx 1 \mathrm{~cm}$. Since the "true" mean wind speed estimate for the Lowenberg et al. data would likely yield still a greater scale, estimates of the refractive index spectrum corresponding to lengths $(\lambda / 2)$ may not be in the inertial subrange for wavelengths of a few centimeters (for a backscattering evaluation). It is of interest to note that the Lowenberg et al. data show an average slope of -1.65 at low frequencies. This is in excellent agreement with the "-5/3" law. At higher frequencies they found an average slope of -2.99 . Here it will be presumed that the inertial and convective subranges coincide and the spectra determinations required may be evaluated in the inertial subrange.

Equations (4.12) and (4.16) may be combined to write

8 There is some uncertainty here because the observations were taken on a tower, but mean wind speed estimates are at the surface. 


$$
F_{x}(k)=\frac{a^{2}}{c} \frac{K_{x}}{K_{m}} \frac{(\operatorname{grad} \bar{x})^{2}}{\left(\partial \bar{u}_{i} / \partial x_{j}\right)^{2}} E(k)
$$

Following Tatarski [61], it is presumed that the mean index of refraction depends only on the vertical coordinate so that

$$
|\operatorname{grad} \overline{\mathrm{N}}|=\frac{10^{-6} \mathrm{Ap}}{\mathrm{T}^{2}}\left\{1+\frac{3.24 \mathrm{~Bq}}{\mathrm{~T}}\right\}\left\{\frac{\partial \theta}{\partial \mathrm{z}}-\frac{1.62 \mathrm{~B}}{1+\frac{3.24 \mathrm{~Bq}}{\mathrm{~T}}} \frac{\partial \mathrm{q}}{\partial \mathrm{z}}\right\}
$$

where $p$ is pressure, $T$ is absolute temperature, $q$ is specific humidity, $\theta$ is potential temperature, and $A$ and $B$ are empirical constants. When $p$ is expressed in millibars, $A \cong 79$ and $B \cong 4800$. Typical values of $q$ in the jet stream vicinity are of the order of $1-300 \mathrm{gm} / 10^{6} \mathrm{gm} \mathrm{[6].} \mathrm{Thus,}$ the term (3.24 Bq/T) may be neglected when compared to unity. However, as suggested by Figs. 12 and 13, after Briggs and Roach [6], the moisture term is not necessarily negligible, as taken by Atlas, Hardy and Naito [2]. Figure 13 illustrates the intrusion of dry stratospheric air into the baroclinic zone below and on the cyclonic side of the jet core. Thus, for

$$
|\operatorname{grad} \bar{N}|=\frac{10^{-6} A p}{T^{2}}\left\{\frac{\partial \theta}{\partial z}-7800 \frac{\partial q}{\partial z}\right\}
$$

the moisture gradient on the upper boundary will serve to decrease the radar return. The moisture contribution on the upper boundary is of the order of $40 \%$ in this instance, but is somewhat less elsewhere. Since this was apparently the most pronounced case during the Briggs and Roach investigation, moisture considerations are also to be omitted here. It 


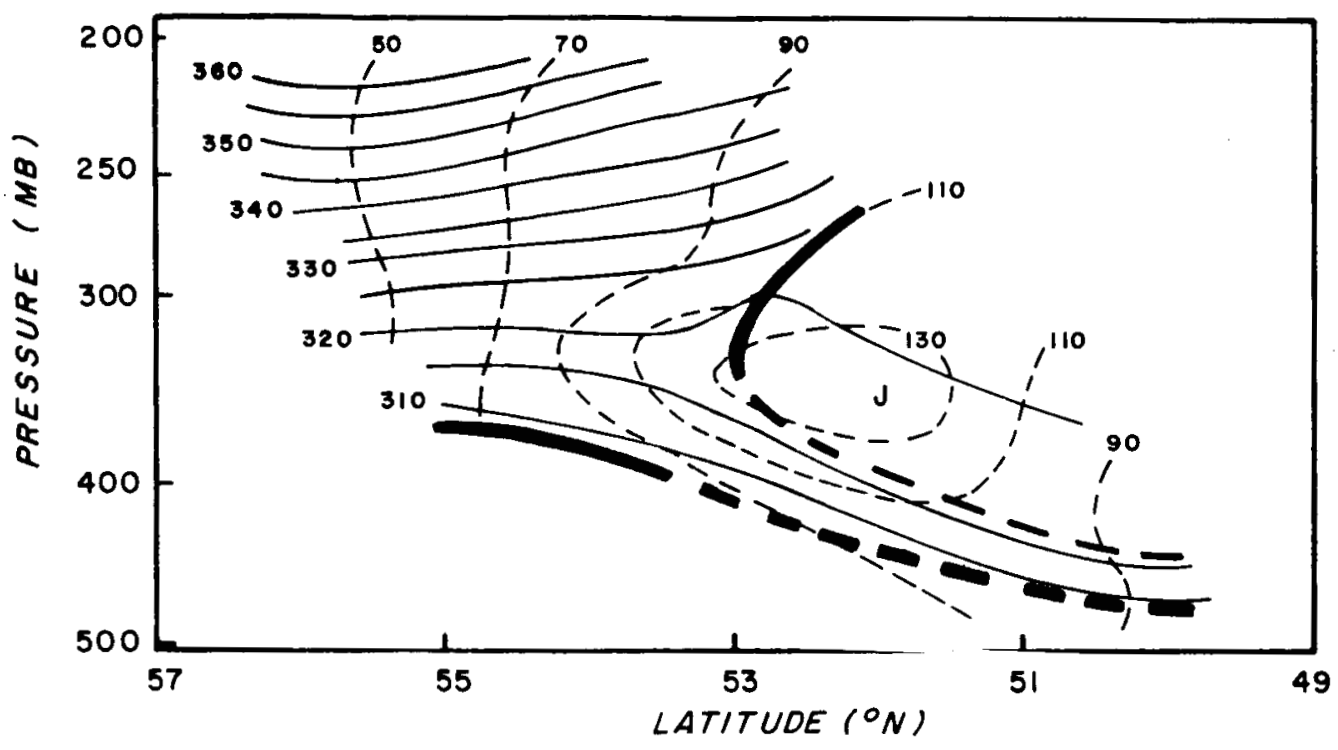

FIG.I2. FLIGHT CROSS SECTION ANALYSIS.

Dashed light lines are lsotochs (KT).

Solid lines denote potential temperature.

(after Briggs and Rooch [6])

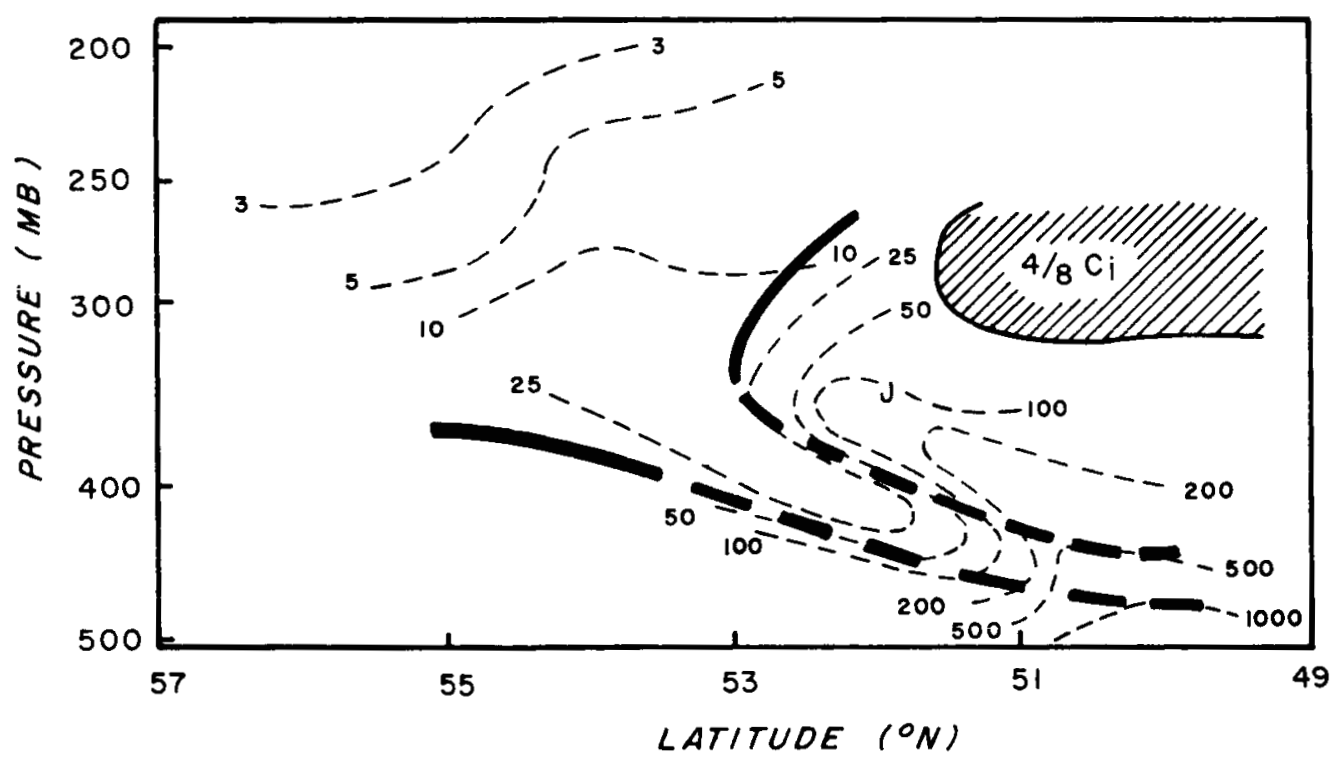

FIG.13. FLIGHT CROSS SECTION ANALYSIS.

Doshed light lines are isopleths of mixing rotio $(G M / 10 \mathrm{GM})$ (after Briggs and Roach [6]) 
should be noted that an enhanced radar return will result from the moisture distribution everywhere but the upper boundary of the jet stream front.

If it is now assumed that $K_{x}$ may be represented adequately by the diffusivity for heat, $K_{h}$, then

$$
F_{N}(k)=\frac{a^{2}\left|R_{f}\right|}{g c} f(p, T)\left|\frac{\partial \theta}{\partial z}\right| F_{\prime}(k),
$$

where

$$
f(p, T)=T^{-3}\left\{79 \times 10^{-6} p(m b)\right\}^{2} .
$$

The approximation $\mathrm{T} \cong \theta$ has been used.

Since there are no measurements of $E(k)$ for $k$ values of interest, it is convenient to rewrite $(4.28)$ as

$$
F_{N}(k)=\frac{a^{2}\left|R_{f}\right|}{g c} f(p, T)\left(\frac{k_{1}}{k}\right)^{5 / 3} E\left(k_{1}\right)\left|\frac{\partial \theta}{\partial z}\right| .
$$

The function $f(p, T)$ may be evaluated with negligible error, a reliable value of $c(\approx 4)$ is available, and $E\left(k_{1}\right)$ has been measured by Reiter and Burns [52] for various intensities of clear-air turbulence. Atlas, Hardy and Naito [2] used $E\left(\frac{2 \pi}{100 \mathrm{~m}}\right)=3.2 \times 10^{6} \mathrm{~cm}^{2} \mathrm{sec}^{-2} / \mathrm{rad} \mathrm{sec}^{-1}$ as indicative of moderate turbulence?,10 This will be used here along with the assumption

9 As indicated by MacCready's results [35], the extrapolation to the centimeter range is probably not in serious error. 10

This is slightly larger than suggested by MacCready [36] and is of the order of surface boundary layer values [62]. 


$$
\mathrm{a}^{2}\left|\mathrm{R}_{\mathrm{f}}\right|=0.1
$$

Since the atmosphere is polytropic to a large extent, $f(p, T)$ is essentially a function of pressure only. A suggested model is shown in Fig. 14. An essentially precise evaluation of $f(p, T)$ can be made for any realization; however, for purposes of estimation, the few per cent deviation from Fig. 14 at any given pressure is of no consequence. The point corresponding to $\mathrm{p}=300 \mathrm{mb}, \mathrm{T}=223 \mathrm{~K}$, after Atlas et al., is also shown. The variation is significant enough to warrant its accounting.

Equation (4.30) can now be written as

$$
F_{N}(k)=3.7 \times 10^{-4} f(p, T)\left|\frac{\partial \theta}{\partial z}\right| k^{-5 / 3}\left(\frac{1}{\frac{\text { radians }}{c m}}\right) .
$$

The principal assumptions used in obtaining (4.32) were: (1) the existence of an inertial subrange, (2) the energy level and extrapolation, and (3) the relation $a^{2}\left|R_{f}\right|=0.1$. The latter is suspect, but since $a^{2}$ is a monotonically decreasing function of the Richardson number, the assumed functional relationship should be indicative of its behavior. As suggested by (4.30), the refractive index spectrum is determined by both the thermal (and moisture in the general case) configuration and the intensity of turbulence.

Before calculating the spectrum for some sample profiles, it may be worthwhile pointing out that eq. (4.32) presumes that moderate turbulence exists. This, of course, implies a vector wind shear, but for $\bar{K}_{\dot{i}}>0.05$, 


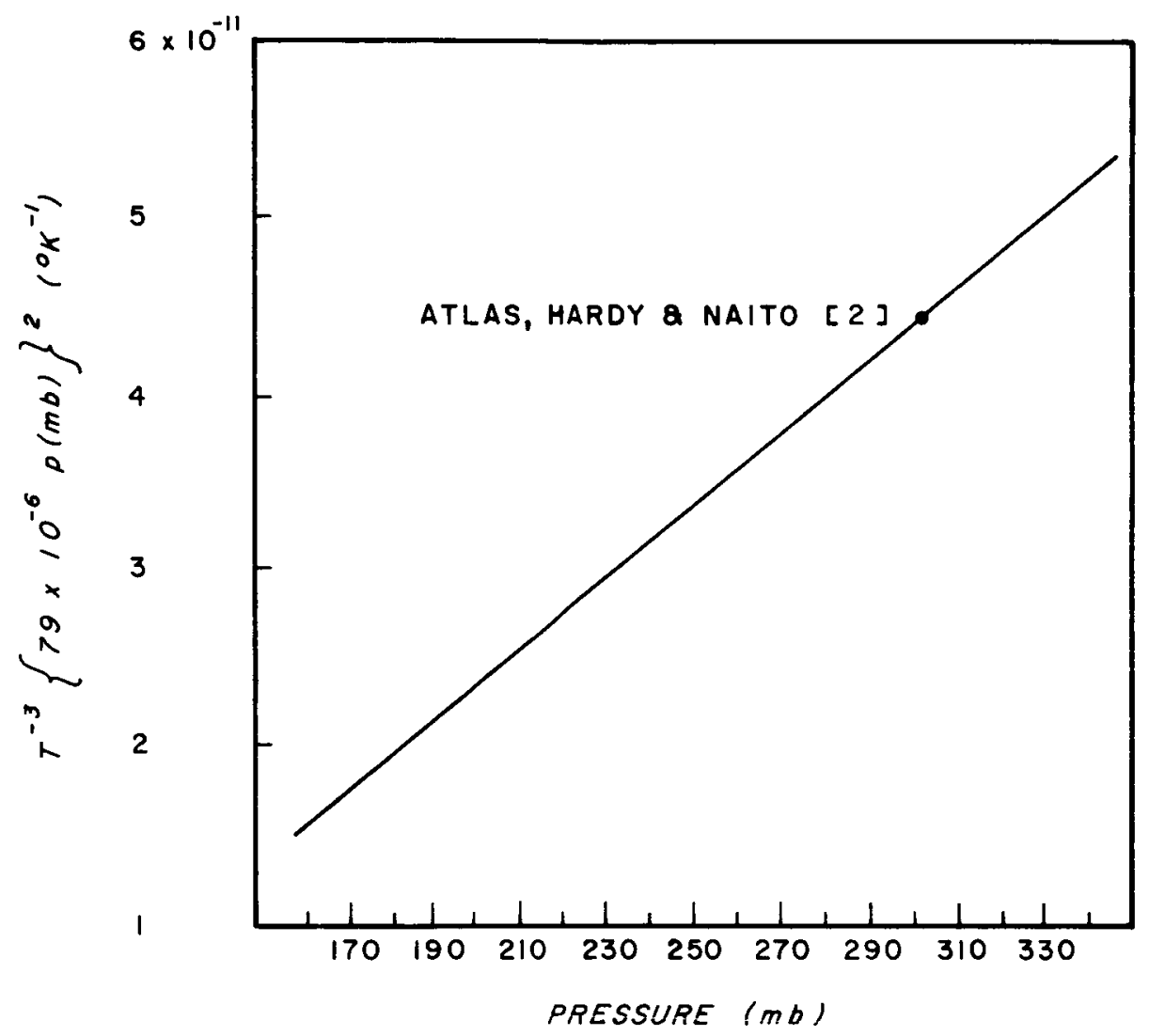

FIG. 14. ASSUMED $f(p, T)$ RELATIONSHIP AS A FUNCTION OF PRESSURE 
consistency is no problem. However, it should be mentioned that more straightforward approaches must cope with consistency. Atlas, Hardy and Naito [2] have evaluated $a^{2}$ for $R_{i}=0.05$ and have stipulated $p, T$ and $\partial \theta / \partial z$. This could be used to imply a wind shear:

$$
\left(\frac{\partial \bar{u}_{i}}{\partial x_{j}}\right)^{2}=\frac{g}{\theta} \frac{\partial \theta / \partial z}{R_{i}}
$$

For their choice of parameters $\mid\left(\frac{\partial u_{i}}{\partial x_{j}}\right) \sim 8 \times 10^{-2} \sec ^{-1}$. While this is quite large, it may be physically realizable. Stinson, Weinstein and Reiter [59] have reported values as high as $5 \times 10^{-2} \mathrm{sec}^{-1}$. However, the concern here is that the choices of $\epsilon$ and $L_{0}$ also imply a wind gradient:

$$
\left(\frac{\partial \bar{u}_{i}}{\partial x_{j}}\right)^{2}=\frac{\epsilon^{2 / 3}}{L_{o}^{4 / 3}} .
$$

Using the minimum $L_{o}\left(10^{4} \mathrm{~cm}\right)$ and $\epsilon=400 \mathrm{~cm}^{2} \mathrm{sec}^{-3}$,

$$
\left|\frac{\partial \bar{u}_{i}}{\partial x_{j}}\right|=1.65 \times 10^{-2} \sec ^{-1}
$$

These shear estimates differ by a factor of five.

The illustration of eq. (4.32) chosen here is taken from data given by Endlich [20] and shown in Fig. 15. The potential temperature gradients along the lines marked A and B were estimated; smoothed profiles are shown in Fig. 16.

The results shown in Fig. 17 are expressed in terms of the coefficient $\mathrm{C}_{\mathrm{N}}^{2}$ for ease in comparison with other results (cf. eq. 4.11). Atlas, Hardy and Naito [2] found that an appropriate range for $C_{\text {iN }}^{2}$ was $10^{-16} \frac{1}{7} 10^{-14} \mathrm{cmi}^{-2 / 3}$. 


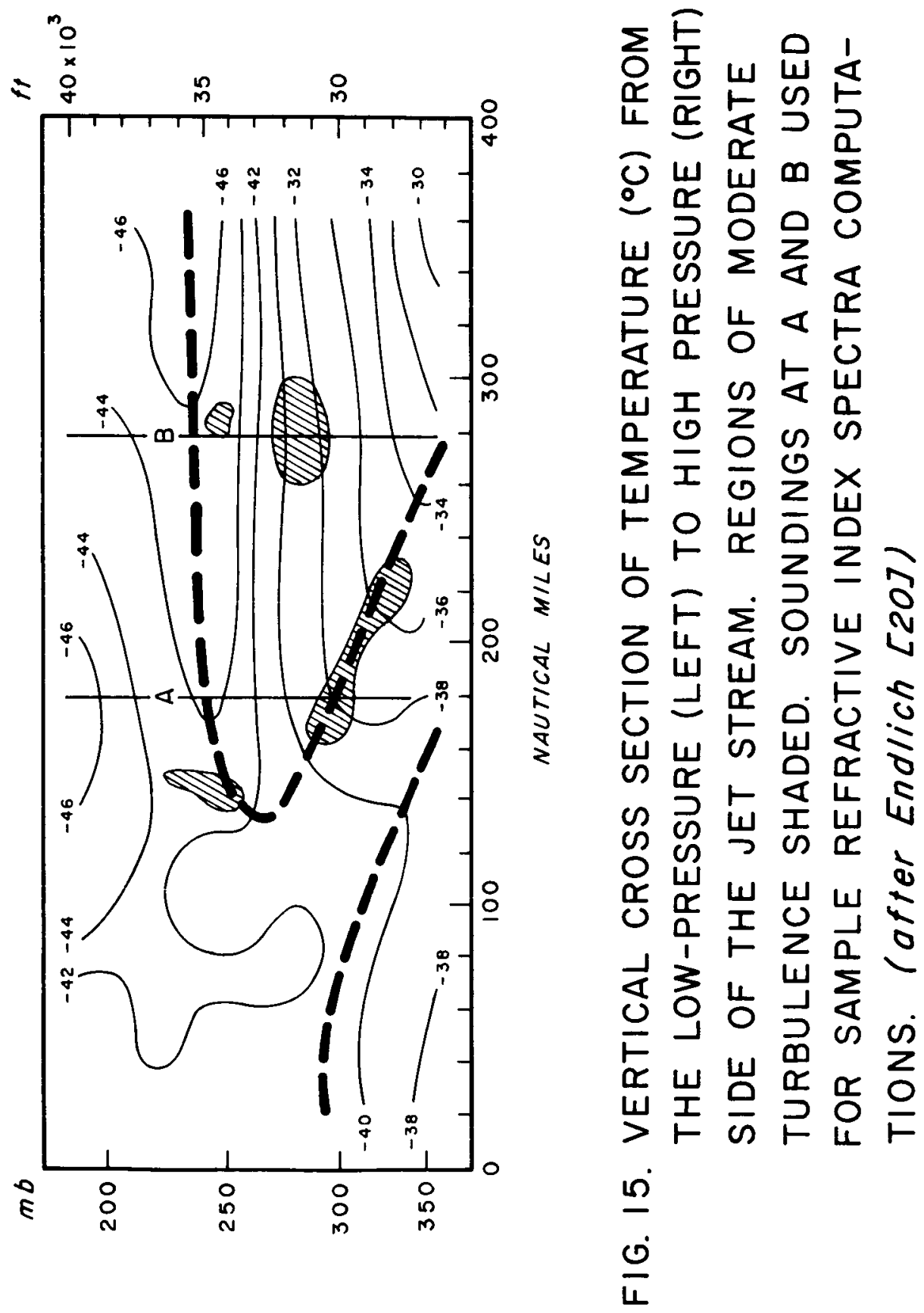




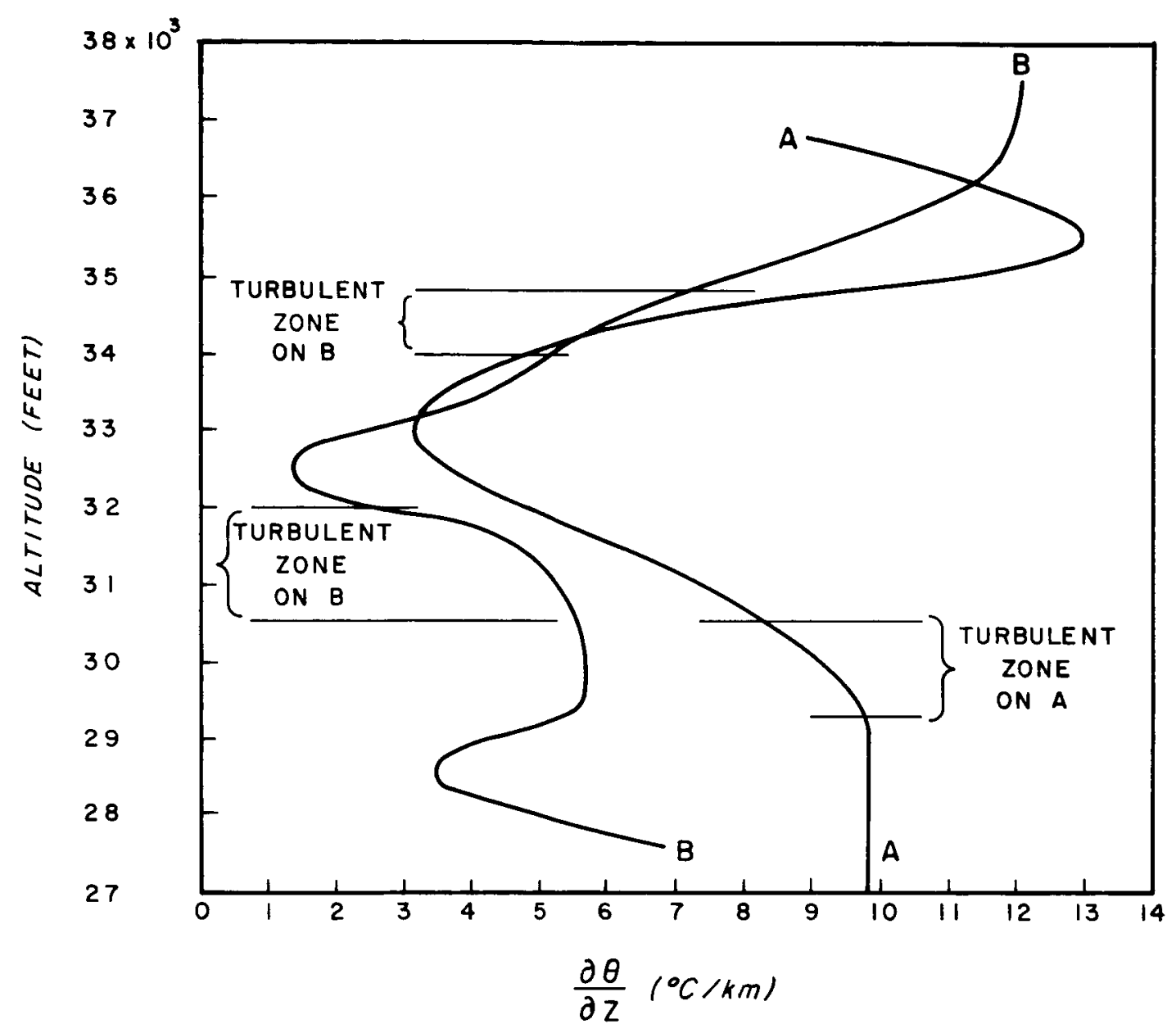

FIG. 16. SMOOTHED PROFILES OF POTENTIAL TEMPERATURE GRADIENT 


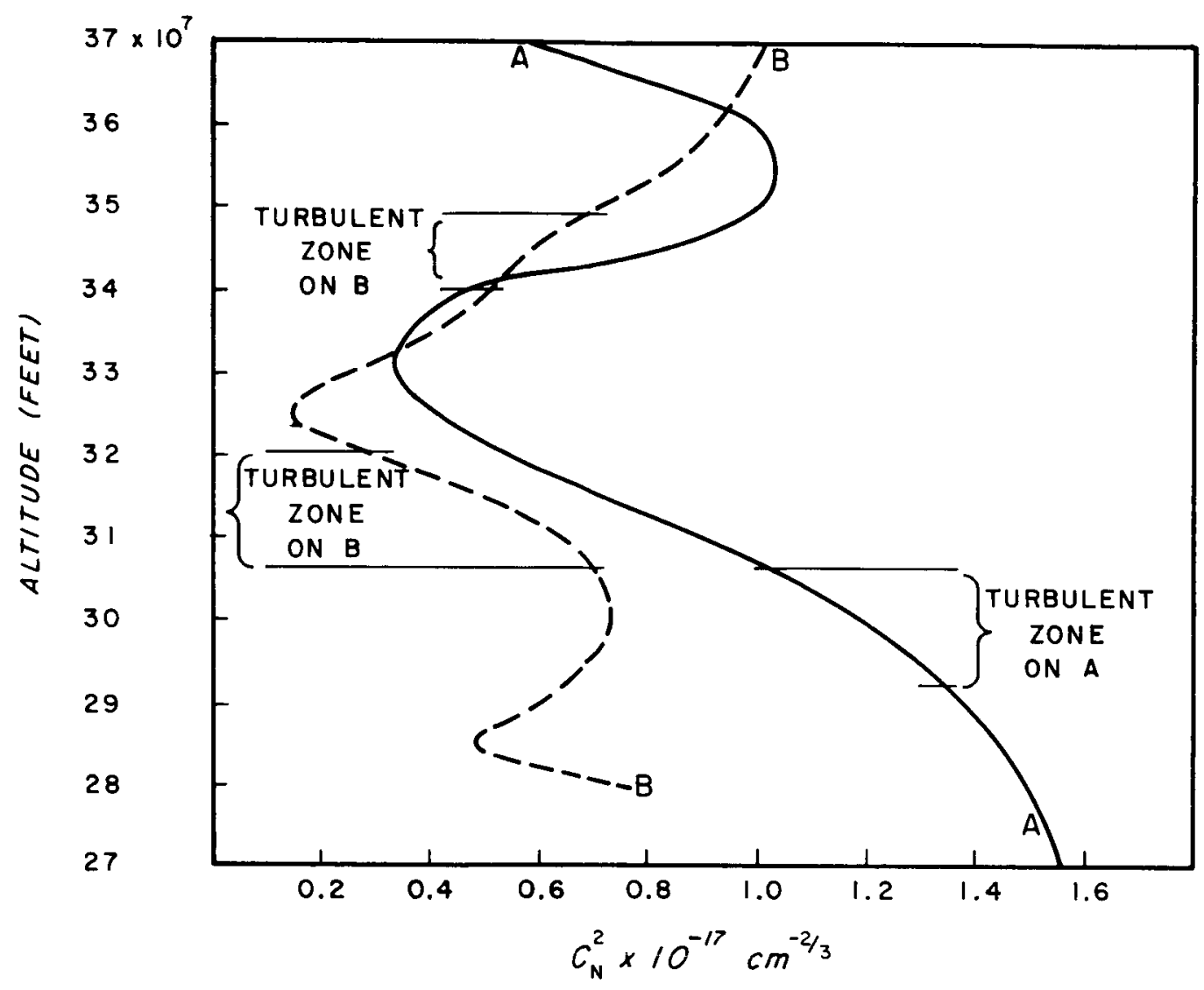

FIG. 17. FLUCTUATION AMPLITUDE COEFFICIENT $C_{N}^{2}$ AS A FUNCTION OF ALTITUDE FOR SOUNDINGS A AND B (see fig. 17) 
The results here are one to three orders of magnitude less. Using an outer scale of $600 \mathrm{~m}$, the $\mathrm{p}, \mathrm{T}$ and $\partial \theta / \partial \mathrm{z}$ values by Atlas et al. , and the relation $a^{2} R_{i}=10^{-1}$, a value $R_{i} \approx 0.06$ is obtained for $C_{N}^{2}=10^{-17}$. Smaller values of $\mathrm{C}_{\mathrm{N}}^{2}$ yield larger $\mathrm{R}_{\mathrm{i}}$. The disparity can be partially explained by noting that for a wind shear of $1.65 \times 10^{-2} \mathrm{sec}^{-1}$ and a lapse rate of $10^{-4} \mathrm{C} / \mathrm{cm}$, Atlas et al. should have evaluated $\left.a^{2}\right|_{R_{i}=1.2} \doteq 1 / 12$. Thus, their results may be overestimated by a factor of 24. This explains a major portion of the discrepancy.

Again, Fig. 17 has been constructed on the tacit assumption that moderate CAT is occurring everywhere. When energy levels (which enter the calculation of $\mathrm{C}_{\mathrm{N}}^{2}$ linearly) are reduced to non-turbulent levels (Wilkins [62]), $C_{N}^{2}$ will be orders of magnitude smaller than indicated in Fig. 17 . 


\section{REFERENCES}

1. Anderson, A. D., 1957: Free-air turbulence. J. Meteor., 14(6), $477-494$.

2. Atlas, D., K. R. Hardy, and K. Naito, 1966: Optimizing the radar detection of clear air turbulence. Paper presented at National Air Meeting on Clear Air Turbulence, Washington, D. C., Feb. 23-24, 1966.

3. Bannon, J. K. , 1951: Meteorological aspects of turbulence affecting aircraft at high altitude. Meteor. Office, Prof. Notes 104.

4. Bannon, J. K., 1951: Severe turbulence encountered by aircraft near jet streams, Meteor. Mag. 80, 262-269.

5. Bindon, H. H. , 1951: Clear air gusts in the upper troposphere over eastern Canada. Weather 6, 152-153.

6. Briggs, J, and W. T. Roach, 1963: Aircraft observations near jet streams. Quart. J. R. Meteor. Soc., 89(380), 225-247.

7. Brundidge, K. C., 1958: A preliminary study of eleven Project Jet Stream flights, 1956-57 phase. Texas A\&M College, Dept. of Ocn. and Meteor., Final Report, Contract AF 19(604)-1565, 86-108.

8. Brundidge, K. C., and J. L. Goldman, 1962: Model cross sections across the jet stream. J. Appl. Meteor., 1(3), 303-317.

9. Burns, A. , and C. K. Rider, 1965: Project TOPCAT power spectral measurements of clear air turbulence associated with jet streams. Royal Aircraft Est., Tech. Rpt. No. 65210, 11 pp.

10. Clem, L. H., 1957: Clear-air turbulence from 25, 000 to 45, 000 feet over the United States. Air Weather Service, Tech. Rpt. No. $105,147 \mathrm{pp}$.

11. Clodman, J., 1953: High level turbulence. Meteor. Branch, Dept. of Transport, Toronto, Toronto, TEC 160, CIR 2332.

12. Clodman, J., G. M. Morgan and J. T. Ball, 1960: High level turbulence. New York University, Dept. of Meteor. and Ocn., Final Report, Contract AF 19(604)-5208, 84 pp. 
13. Colson, D., 1961: Analysis of clear air turbulence during April 1960. Monthly Wea. Rev., 89(3), 94-98.

14. Colson, D., 1963: Analysis of clear air turbulence data for March 1962. Monthly Wea. Rev., 91(2), 73-82.

15. Colson, D., 1966: Nature and intensity of clear air turbulence. Paper presented at National Air Meeting on Clear Air Turbulence, Washington, D. C. , Feb. 23-24, 1966.

16. Conover, J. H., 1960: Cirrus patterns and related air motions near the jet stream as derived by photography. J. Meteor., 17(5), $532-546$.

17. Cunningham, No W., 1958: A study of the duration of clear-air turbulence near the jet stream and its relation to horizontal temperature gradient. Texas A\&M College, Dept. of Ocn. and Meteor., Final Report, Contract AF 19(604)-1565, 75-85.

18. Endlich, R. M. , and G. S. Mclean, 1957: The structure of the jet stream core. J. Meteor., 14(6), 543-552.

19. Endlich, R, M., 1963: The detailed structure of the atmosphere in regions of clear-air turbulence. Final Report, SRI Project No. 4055, Contract Cwb-10324, 62 pp.

20. Endlich, R, M., 1964: The mesoscale structure of some regions of clear-air turbulence. J. Appl. Meteor., 3(3), 261-276.

21. Endlich, R. M., and G. S. McLean, 1965: Jet-stream structure over the central United States determined from aircraft observations. J. Appl. Meteor., 4(1), 83-90.

22. Endlich, R. M., and R. L. Mancuso, 1965: On the analysis of clear air turbulence by use of rawinsonde data. Monthly Wea. Rev., $93(1), 47-58$.

23. Estoque, M. A., 1958: Some characteristics of turbulence at high altitudes. GRD Research Notes, $10 \mathrm{pp}$.

24. Heath-Smith, J. R., 1955: Turbulence encountered by Comet I aircraft. Farnborough, England, Royal Aircraft Establishment, Rep. Structures 179.

25. Hislop, G. S., 1951: Clear air turbulence over Europe. J. Roy. Aeronaut: Soc., 55, 185-225. 
26. Hyde, E. A., 1954: High altitude air turbulence. Flight, 65; 492-493.

27. Jenkins, C. F., 1952: Forecasting the mountain wave. GRD, Air Force Surveys in Geophysics, No. 15, 32 pp.

28. Keitz, E. L., 1959: Differential advection as a factor in clear-air turbulence, J. Meteor., $16(1), 57-62$.

29. Kronebach, G. W., 1964: An automated procedure for forecasting clear-air turbulence. J. Appl. Meteor., 3(2), 119-125.

30. Kuettner, J., 1952: Note on high level turbulence encountered by a glider. Air Force Surveys in Geophys. No. 29.

31. Lake, H., 1956: A meteorological analysis of clear-air turbulence. Geophysical Res. Papers, No. 47, AFCRC, 63 pp.

32. Lowenberg, E. C., F. X. Bostick, Jr., and C. E. McCullough, 1960: Frequency spectra analyses of one millisecond time response temperature sensors at various levels near the ground. The University of Texas, EERL Rpt. 6-32, Contr. AF 19(604)-2249, 55 pp.

33. Lumley, J. L., and H. A. Panofsky, 1964: The structure of atmospheric turbulence. Interscience, $239 \mathrm{pp}$.

34. Lyra, G., 1940: Über den Einfluss von Bodenerhebungen auf die Strömung einer stabil geschichteten Atmosphäre. Beitr. Phys. fr. Atmos., 16, 197-206.

35. MacCready; P. B., 1962: Turbulence measurements by sailplane. J. Geophys. Res., 67 (3), 1041-1050.

36. MacCreadys P. B. , 1964: Standardization of gustiness values from aircraft. J. Appl. Meteor., 3(4), 439-449.

37. Megaw, E.C.S., 1957: Fundamental radio scatter propagation theory. Proc. IEEE, 104C, 441-455.

38. Murray, R., 1953: The upper troposphere and lower stratosphere near jet streams: an examination of observations made by the Meteorological Research Flight, Farnborough. Meteor.Res. Paper No. 813.

39. Panofsky, H. A., and F. Pasqui11, 1963: The constant of the Kolmogorov law. Quart.J.R. Mieleur. Soc., 89(382), 550-551. 
40. Pao, Y., 1965: Structure of turbulent velocity and scalar fields at large wave numbers. Phys. Fluids, 8(6), 1063-1075.

41. Petterssen, S., and W. C. Swinbank, 1947: On the application of the Richardson criterion to large-scale turbulence in the free atmosphere. Quart.J.R. Meteor. Soc., 73, 335-345.

42. Pinus, N. Z., 1957: Atmospheric turbulence of dimensions which affect aircraft. Izv. Akad. Nauk SSR, Ser. Geofig. No. 3, $395-400$.

43. Press, H., M. H. Schindlcr and J. K. Thompson, 1953: Summary of pilots' reports of clear-air turbulence at altitudes above 10,000 feet. NACA Res. Memo. RML 52L30a.

44. Radok, U., and R. H. Clarke, 1958: Some features of the sub-tropical jet stream. Beitr. Phys. d. Atmos., 31(1/2), 89-108.

45. Reiter, E. R., 1961: The detailed structure of the wind field near the jet stream. J. Meteor., $18(1), 9-30$.

46. Reiter, E. R., 1962: On the nature of clear-air turbulence (CAT). Aerospace Engineering, 21 (11), 39-46.

47. Reiter, E.R., 1963: Jet-stream Meteorology, Univ. Chicago Press, $515 \mathrm{pp}$.

48. Reiter, E. R., 1963: A case study of severe clear-air turbulence. Archiv. f. Meteor., Geophys. und Bioklimat., Series A, Bd. 13, 3-4, 379-389.

49. Reiter, E. R., and A. Nania, 1964: Jet-stream structure and clearair turbulence (CAT). J.Appl. Meteor.: 3(3), 247-260.

50. Reiter, E. R. , 1964: Jet streams and turbulence. Austra. Meteor. Mag., No. 45, 13-33.

51. Reiter, E.R., 1964: CAT and SCAT. Astronautics and Aerospace Eng。, 2, 60-65.

52. Reiter, E. R., and A. Burns, 1966: The structure of clear-air turbulence derived from "TOPCAT" aircraft measurements. J. Atmos. Sci。, $23(2), 206-212$.

53. Rustenbeck: J. D. : 1963: The association of Richardson's criterion with high level turrbulcnce. Monthly Wea. Revo: 91(4), 193-198. 
54. Sasaki, Y., 1958: A theory and analysis of clear-air turbulence. Texas A\&M College, Dept. of Ocn, and Meteor., Sci. Rept. No. 1, Contract AF 19(604)-1565, 75 pp.

55. Schwerdtfeger, W., and U. Radok, 1959: Hodograph analysis as applied to the occurrence of clear-air turbulence. J. Meteor., $16(5), 588-592$.

56. Scorer, R. S., 1949: Theory of waves in the lee of mountains. Quart.J.R. Meteor.Soc., 75(323), 41-56.

57. Serebreny, S. M., E. J. Wiegman and R. G. Hadfield, 1962: Some characteristic features of the jet stream complex during selected synoptic situations. J.Appl. Meteor., 1(2), 137-153.

58. Staras, H., and A. D. Wheelon, 1959: Theoretical research on tropospheric scatter propagation in the United States. IRE Trans. Ant. Prop., AP-7(1), 80-87.

59. Stinson, R., A. I. Weinstein and E. R. Reiter, 1964: Details of wind structure from high resolution balloon soundings. NASA Tech. Memo. X-53115, 22 pp.

60. Tatarski, V. I., 1960: Radiophysical methods for the investigation of atmospheric turbulence. Radiofizika, 3(4), 551-583.

61. Tatarski, V. I., 1961: Wave propagation in a turbulent medium. (Translation by R. A. Silverman), McGraw-Hill, 285 pp.

62. Wilkins, E. M., 1963: Decay rates for turbulent energy throughout the atmosphere. J.Atmos. Sci., 20(5), 473-476. 